\title{
Hypoxia, Metabolic Reprogramming, and Drug Resistance in Liver Cancer
}

\author{
Macus Hao-Ran Bao ${ }^{1}$ and Carmen Chak-Lui Wong ${ }^{1,2, *}$ \\ 1 Department of Pathology, The University of Hong Kong, Hong Kong, China; macusbao@gmail.com \\ 2 State Key Laboratory of Liver Research, The University of Hong Kong, Hong Kong, China \\ * Correspondence: carmencl@pathology.hku.hk
}

check for

updates

Citation: Bao, M.H.-R.; Wong, C.C.-L. Hypoxia, Metabolic Reprogramming, and Drug Resistance in Liver Cancer. Cells 2021, 10, 1715. https://doi.org/ 10.3390/cells10071715

Academic Editor: Daniele M. Gilkes

Received: 31 May 2021

Accepted: 3 July 2021

Published: 6 July 2021

Publisher's Note: MDPI stays neutral with regard to jurisdictional claims in published maps and institutional affiliations.

Copyright: (C) 2021 by the authors. Licensee MDPI, Basel, Switzerland. This article is an open access article distributed under the terms and conditions of the Creative Commons Attribution (CC BY) license (https:/ / creativecommons.org/licenses/by/ $4.0 /)$.

\begin{abstract}
Hypoxia, low oxygen $\left(\mathrm{O}_{2}\right)$ level, is a hallmark of solid cancers, especially hepatocellular carcinoma (HCC), one of the most common and fatal cancers worldwide. Hypoxia contributes to drug resistance in cancer through various molecular mechanisms. In this review, we particularly focus on the roles of hypoxia-inducible factor (HIF)-mediated metabolic reprogramming in drug resistance in HCC. Combination therapies targeting hypoxia-induced metabolic enzymes to overcome drug resistance will also be summarized. Acquisition of drug resistance is the major cause of unsatisfactory clinical outcomes of existing HCC treatments. Extra efforts to identify novel mechanisms to combat refractory hypoxic HCC are warranted for the development of more effective treatment regimens for HCC patients.
\end{abstract}

Keywords: hypoxia; metabolism; metabolic reprogramming; drug resistance; TKIs; ICIs; liver cancer

\section{Introduction}

Hepatocellular carcinoma (HCC), the most common liver malignancy (70-90\%) arising from aberrant hepatocyte transformation, is the fifth-most prevalent cancer worldwide with more than 840,000 new cases and over 780,000 deaths in 2018 [1]. Due to the asymptomatic nature of HCC at early stage, most patients are diagnosed at advanced stage with limited therapeutic options. Intratumoral hypoxia, low oxygen $\left(\mathrm{O}_{2}\right)$ level, is a crucial feature in all solid tumors, especially HCC. Hypoxia elicits a cascade of metabolic changes for hypoxic adaptation in HCC cells mostly via hypoxia-inducible factors (HIFs), the master transcription factors for hypoxic response. While hypoxia leads to drug resistance in HCC [2,3], the underlying molecular mechanisms remain largely elusive. Sorafenib was the first FDA-approved tyrosine kinase inhibitor (TKI) for first-line HCC treatment but patients quickly acquired drug resistance after three months [4,5]. Other TKIs, including Lenvatinib and Cabozantinib (first-line) as well as Regorafenib and Ramucirumab (secondline), were used as HCC palliative treatments but the survival benefits were modest [6-10]. Recently, immune checkpoint inhibitors (ICIs), Nivolumab and pembrolizumab were approved by FDA as a second-line treatment strategy. Tumor microenvironment (TME) is immunosuppressive with anti-tumoral immune cells, including CD8+ cytotoxic T cells and natural killer (NK) cells being exhausted and increased number of protumoral immune cells, including M2-like macrophages, regulatory T cells (Treg) and myeloid-derived suppressor cells (MDSC) [11,12]. PD-1 is an immune checkpoint suppressing immune cell activities to prevent overactivation of immune system upon binding with its ligand, PD-L1. Cancer cells hijack this pathway to evade immune surveillance by expressing PD-L1 [13]. Only 20\% HCC patients were responsive to Nivolumab, an anti-PD-1 monoclonal antibody that inhibits PD-1/PD-L1 ligation [9]. Drug resistance in HCC profoundly impedes longterm clinical benefits of existing treatments. Therefore, there is an urgent clinical need to overcome drug resistance in refractory HCC. We will discuss the role of hypoxia-mediated metabolic reprogramming, which contributes to drug resistance of TKIs and ICIs, and 
the potential of combining drugs targeting the associated genes with TKIs and ICIs to overcome drug resistance in hypoxic HCC.

\section{Hypoxic Tumor Microenvironment in HCC}

HCC is one of the most hypoxic malignancies [14,15]. The median partial pressure of $\mathrm{O}_{2}\left(\mathrm{pO}_{2}\right)$ in normal human liver tissue is $30 \mathrm{mmHg}$ while intratumoral region of human liver tumors is merely $6 \mathrm{mmHg}[14,15]$. $74.1 \% \mathrm{HCC}$ tumor regions in rat had low $\mathrm{pO}_{2}$ ranging from 0 to $10 \mathrm{mmHg}$ [16]. Another study in rat HCC model showed that while $\mathrm{pO}_{2}$ in nontumorous liver tissues reached $45 \mathrm{mmHg}, \mathrm{O}_{2}$ tension in HCC tissues was only 0.2 to $0.8 \mathrm{mmHg}$ [17]. Furthermore, IHC studies revealed significantly higher expression of hypoxic markers, including HIF-1 $\alpha$ [18], glucose transporter type 1 (GLUT1) [19], lactate dehydrogenase A (LDHA) [20] and carbonic anhydrase 9 (CA9) [21] in human HCC tissues when compared to nontumorous liver tissues. These data consolidate that HCC is highly hypoxic. Intratumoral hypoxia is caused by an imbalance of $\mathrm{O}_{2}$ availability due to insufficient blood supply from poor tumor vasculature, and increased $\mathrm{O}_{2}$ consumption by metabolic active HCC cells. HCC cells experience a continuum of $\mathrm{O}_{2}$ concentration gradient as tumor regions distant from the blood vessel become increasingly hypoxic (Figure 1). While tumor area with close proximity with the blood vessel is oxygenated, $\mathrm{O}_{2}$ level gradually decreases away from blood vessels, forming hypoxic regions [22]. Necrotic regions at the tumor core are severely hypoxic. Hypoxia in HCC is dynamic. Spatial pattern and intensity of hypoxia vary temporally according to heterogeneity of $\mathrm{O}_{2}$ level in the TME. Moreover, HCC treatment, transcatheter arterial embolization transcatheter (TAE) and arterial chemoembolization (TACE), which initially attempted to restrict blood supply to mitigate tumor growth, inadvertently aggravates hypoxia [23]. Tyrosine kinase inhibitors (TKIs) also aggravate intratumoral hypoxia by inhibiting multiple kinase targets, including vascular endothelial growth factor (VEGF), platelet-derived growth factor (PDGF) and fibroblast growth factor (FGF), that otherwise promote angiogenesis [21]. Hypoxia induces a series of alterations of metabolic pathways via HIFs that promotes drug resistance, leading to unsatisfactory clinical outcomes in HCC patients.
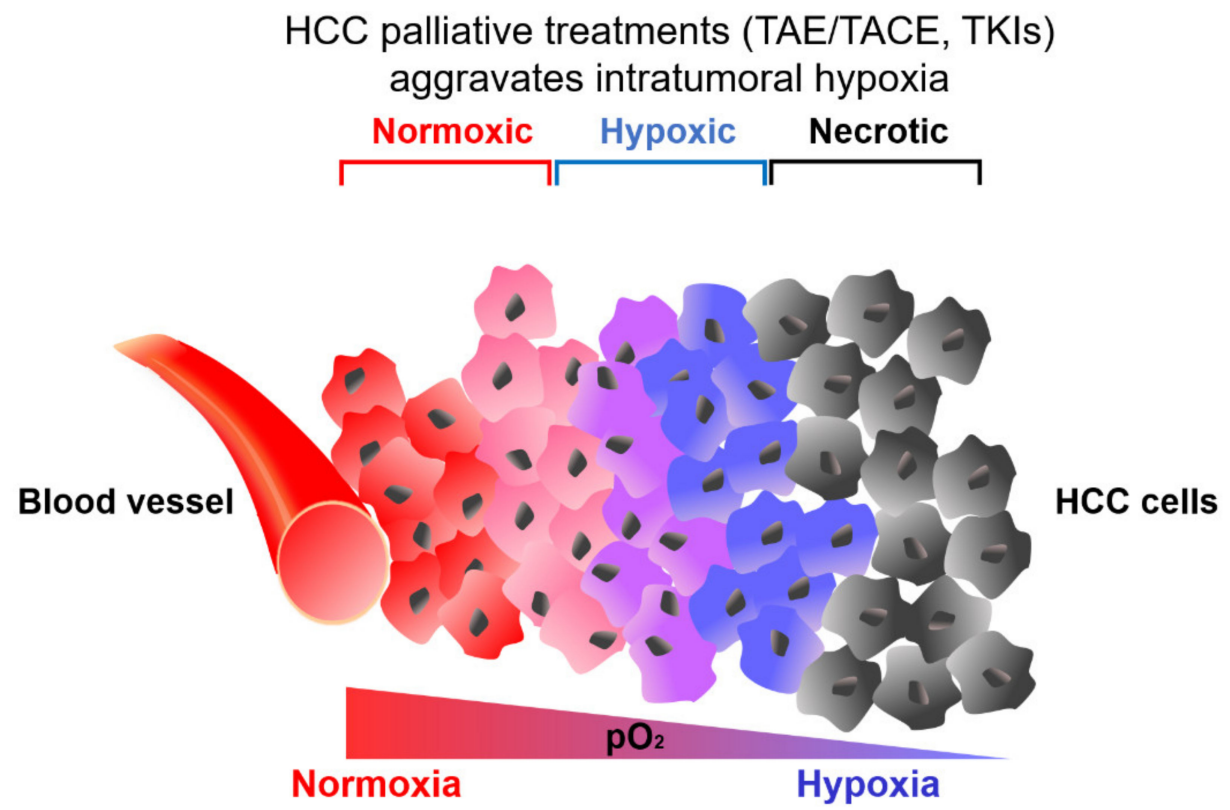

Figure 1. Hypoxic tumor microenvironment (TME) in hepatocellular carcinoma (HCC). A gradually decreasing gradient of partial pressure of $\mathrm{O}_{2}\left(\mathrm{pO}_{2}\right)$ in HCC from the blood vessel. Tumor regions that are close to the blood vessel are more oxygenated whereas regions away from the blood vessel are hypoxic. HCC treatments including arterial embolization transcatheter (TAE), arterial chemoembolization (TACE) and tyrosine kinase inhibitors (TKIs) inadvertently induced hypoxia in HCC. 


\section{HIF-Induced Metabolic Reprogramming under Hypoxia and Drug Resistance in HCC}

Under normoxia, glucose is broken down to pyruvate during glycolysis. Subsequently, pyruvate is converted to acetyl coenzyme A (acetyl-CoA), which enters tricarboxylic acid cycle (TCA) cycle to produce electron donors, nicotinamide adenine dinucleotide (NADH) and flavin adenine dinucleotide (FADH2) (Figure 2A). Electrons pass along electron transport chain (ETC) at mitochondria, and eventually to $\mathrm{O}_{2}$, the final electron acceptor to produce adenosine triphosphate (ATP) (Figure 3). This process is oxidative phosphorylation (OXPHOS). Normoxic cells exhibit high OXPHOS activity to maximize energy production for growth and proliferation. Under hypoxia with limited $\mathrm{O}_{2}$, electron transfer at ETC is not efficient due to the lack of final electron acceptor, leading to electron leakage and high reactive oxygen species (ROS) production from mitochondria. Excessive ROS accumulation results in irreversible oxidative damage of cellular components, eventually leading to cell death. Under hypoxia, HIFs upregulated pyruvate dehydrogenase kinase 1 (PDK1) to inhibit PHD activity, thus inhibiting conversion of pyruvate to acetyl-CoA $[24,25]$. At the same time, HIFs upregulated LDHA to promote conversion of pyruvate to lactate [26]. HIF-mediated PDK1 and $L D H A$ transactivation leads to the switch from oxidative to glycolytic metabolism [27] (Figure 2B), thus preventing deleterious buildup of mitochondrial ROS under hypoxia. Furthermore, glycolytic metabolite, 3-phosphoglyceric acid (3PG), enters serine synthesis pathway (SSP) generating serine, which enters the folate cycle to provide a source of nicotinamide adenine dinucleotide phosphate (NADPH) to counteract ROS. Interestingly, enzymes in the SSP and folate cycle are consistently induced by hypoxia/HIFs [28]. Since induction of oxidative stress is an important mechanism for antitumoral effect of TKIs [29], metabolic rewiring under hypoxia contributes to drug resistance by lowering ROS in TKI-treated HCC. Moreover, levels of metabolites, including glucose, lactate and adenosine were altered in TME that collectively shape an immunosuppressive environment to greatly hinder the efficacy of ICIs in HCC.

\subsection{HIF-Mediated Induction of Glucose Metabolism under Hypoxia}

Glucose uptake and glycolysis are activated in hypoxic HCC cells. HIF-1 induces the expression of solute carrier family 2 member 1 (SLC2A1) and solute carrier family 2 member 3 (SLC2A3), which encode GLUT1 and GLUT3 respectively, to promote glucose uptake to meet the insatiable demand of glucose for growth of hypoxic cancer cells [30] (Figure 3) (Table 1). PET-CT imaging found that uptake of fluorodeoxyglucose (FDG), a glucose analog, increased with decreasing $\mathrm{O}_{2}$ availability in cancer cells [31]. Human HCC with high FDG uptake had significantly higher expression of GLUT1 and GLUT3, and these patients had shorter overall survival [32]. Most glycolytic genes, including hexokinase $(H K)$, phosphofructokinase, liver type $(P F K L)$, aldolase $(A L D)$, triosephosphate isomerase 1 (TPI), glyceraldehyde-3-phosphate dehydrogenase (GAPDH), phosphoglycerate kinase $(P G K)$, enolase 1 (ENO1) and pyruvate kinase M1/2 (PKM), were induced by hypoxia and/or HIF-1 (Table 1) [30]. HK is the first rate-limiting enzyme of glycolysis (Figure 3). While normal hepatocytes express $\mathrm{HK} 4, \mathrm{HK} 2$ isoform is predominantly overexpressed in HCC [33]. The protein level of HK2 was significantly increased in multiple HCC cell lines cultured in hypoxia [34]. HK2 upregulation was mediated by HIF-1 [34]. Alternatively, HIF1 mediated suppression of $m i R-199 a$, which otherwise targets HK2 for its downregulation, to induce HK2 expression in hypoxic HCC cells [35]. Upregulation of HK2 promoted glycolysis and increased lactate secretion in hypoxic HCC cells. GLUT1/3 and HK2 are prognostic markers in HCC patients. Clinically, overexpression of GLUT1/3 and HK2 was associated with poor clinical outcomes, including more advanced tumor stage, greater tumor burden, higher rate of recurrence and poor survival in HCC patients [19,32,36]. 


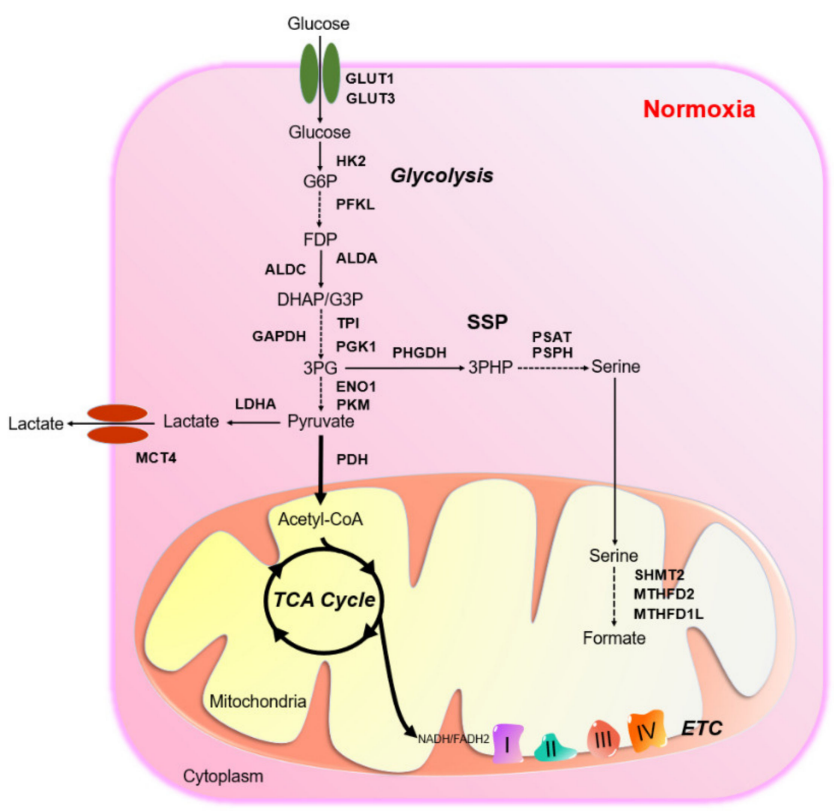

(a)

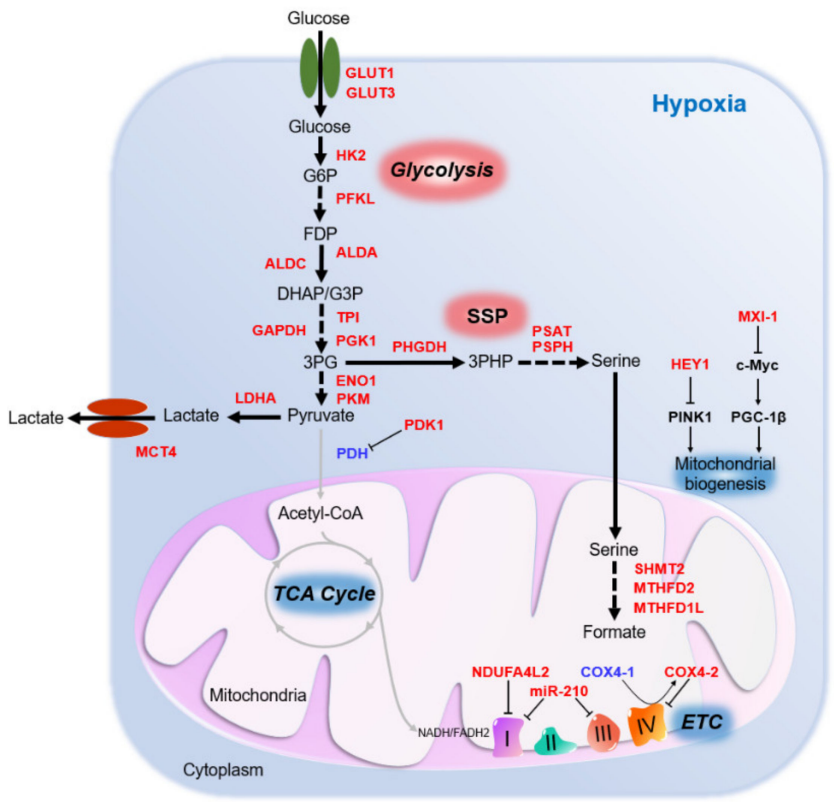

(b)

Figure 2. Hypoxia-inducible factors (HIFs) divert metabolites from tricarboxylic acid cycle (TCA) cycle to glycolysis under hypoxia. (a) Under normoxia, glucose is converted to pyruvate during glycolysis. Pyruvate is then converted to acetyl coenzyme A (acetyl-CoA), which fuels the TCA cycle for maximum adenosine triphosphate (ATP) production with ample oxygen $\left(\mathrm{O}_{2}\right)$ supply. (b) Under hypoxia, metabolism is switched from oxidative to glycolytic metabolism by HIF-dependent upregulation of pyruvate dehydrogenase kinase 1 (PDK1) and (lactate dehydrogenase A) LDHA. Lactate export is promoted to prevent excessive intracellular lactate accumulation, which may lead to cytoplasmic acidification. Serine synthesis pathway (SSP) and its downstream folate cycle are activated. Folate cycle produces a major antioxidant, nicotinamide adenine dinucleotide phosphate (NADPH), to counteract oxidative stress under hypoxia. Mitochondrial activity and biogenesis are suppressed to reduce mitochondrial reactive oxygen species (ROS) production. Genes or pathways highlighted in red: upregulated by HIFs. Genes or pathways highlighted in blue: downregulated by HIFs. 


\section{Electron Transport Chain (ETC)}

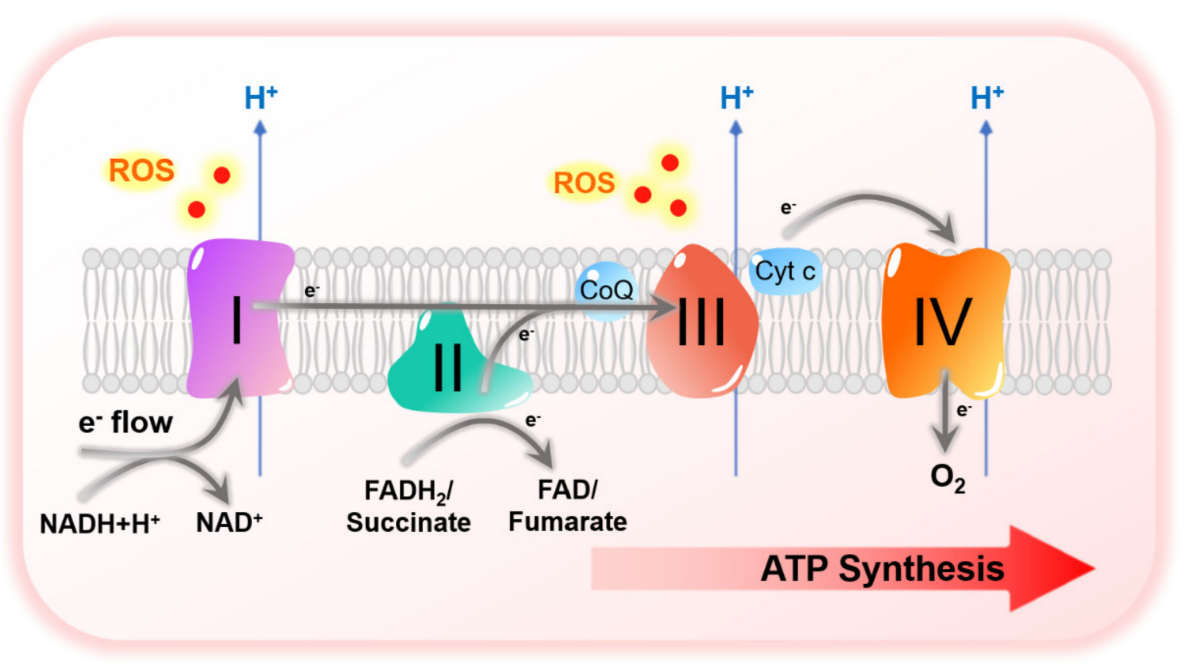

Figure 3. Electron transport chain (ETC). ETC is located at mitochondrial inner membrane (MIM). Electron donors produced from glycolysis and TCA cycle, nicotinamide adenine dinucleotide $(\mathrm{NADH})$ and flavin adenine dinucleotide (FADH2), and succinate (glucose intermediate) donate electrons to the ETC. Electrons pass through ETC complex I to IV and finally to $\mathrm{O}_{2}$, the final electron accepter. Electron flow drives $\mathrm{H}^{+}$export to the intermembrane space, creating a transmembrane electrical potential to drive ATP synthesis. Premature electron leakage leads to ROS accumulation, especially at complex I and complex III.

Table 1. Hypoxia-induced alterations of different metabolic pathways, their associated genes and their clinical relevance in human HCC.

\begin{tabular}{|c|c|c|c|}
\hline Metabolic Pathways & Genes & HIF-Inducible & Expression in Human HCC \\
\hline \multirow{2}{*}{$\begin{array}{l}\text { Glucose Metabolism } \\
\text { (Activated) }\end{array}$} & $\begin{array}{l}\text { GLUT1, GLUT3, HK2, } \\
\text { ALDA and GAPDH }\end{array}$ & Yes [30] & Overexpressed $[19,32,36-40]$ \\
\hline & $\begin{array}{l}\text { PFKL, ALDC, TPI, PGK1, } \\
\text { ENO1 and PKM }\end{array}$ & Yes [30] & Undetermined \\
\hline $\begin{array}{l}\text { Lactate Metabolism } \\
\text { (Activated) }\end{array}$ & $L D H A$ and $M C T 4$ & Yes $[26,41,42]$ & Overexpressed $[20,43]$ \\
\hline \multirow[t]{2}{*}{ Mitochondrial Metabolism (Suppressed) } & $\begin{array}{c}\text { PDK1, NDUFA4L2, } \\
\text { COX4-2, miR-210, HEY1 }\end{array}$ & Yes [44-49] & Overexpressed $[46,50,51]$ \\
\hline & MXI-1 & Yes [52] & Undetermined \\
\hline \multirow{2}{*}{$\begin{array}{l}\text { Serine Synthesis Pathway and Folate Cycle } \\
\text { (Activated) }\end{array}$} & $\begin{array}{l}\text { PHGDH, PSPH, SHMT2, } \\
\text { MTHFD2 and MTHFD1L }\end{array}$ & Yes [28] & Overexpressed [53-56] \\
\hline & PSAT & Yes [28] & Undetermined \\
\hline Adenosinergic Metabolism (Activated) & CD39/CD39L1 and CD73 & Yes [57] & Overexpressed $[58,59]$ \\
\hline
\end{tabular}

3.1.1. HIF-Mediated Induction of Glucose Metabolism under Hypoxia and TKI Resistance

Drug resistant cancer cells relied heavily on glucose metabolism for survival under hypoxia [60]. HIF-mediated glycolysis contributes to Sorafenib resistance in multiple HCC cell lines [61]. GLUT1, GLUT3 and HK2 were overexpressed in Sorafenib resistance HCC cells [40,61-63]. Sorafenib-resistant HCC cells (Huh-7R) had markedly higher glucose uptake and lactate production rates, indicative of augmented glycolysis [61,64]. Previous studies demonstrated that activation of glucose metabolism under hypoxia is a targetable vulnerability to re-sensitize drug resistant HCC cells. 2-Deoxyglucose (2-DG), a glycolysis inhibitor, significantly potentiated toxicity of Sorafenib by reducing cell viability, inhibit- 
ing colony formation and promoting G0/G1 cell cycle arrest of Sorafenib resistant HCC cells [64]. Importantly, 2-DG synergized with Sorafenib to markedly induce apoptosis of Sorafenib resistant HCC cells (Table 2) [63]. Inhibition of another important glycolytic enzyme, HK2, by 3-bromopyruvate (3-BP) also greatly improved the efficacy of Sorafenib in hypoxic HCC cells (Table 2) [40]. Combination treatment of 3-BP and Sorafenib significantly attenuated HCC growth, demonstrating the importance of glycolysis activation for drug resistance in hypoxic HCC [40].

Table 2. Combination treatments of inhibitors targeting genes in metabolic pathways altered by HIFs with TKIs or ICIs to overcome drug resistance in hypoxic HCC.

\begin{tabular}{|c|c|c|c|}
\hline Inhibitors & Targets & Combination Treatment & $\begin{array}{l}\text { Synergistic Effects on } \\
\text { Hypoxic HCC }\end{array}$ \\
\hline 2-DG & Glycolysis & Sorafenib (TKI) & $\begin{array}{l}\text { Reduced cell viability, induced oxidative } \\
\text { stress and apoptosis }[63,64]\end{array}$ \\
\hline 3-BP & $\begin{array}{c}\mathrm{HK} 2 \\
\text { (glycolysis) }\end{array}$ & Sorafenib (TKI) & $\begin{array}{l}\text { Reduced cell viability in vitro and } \\
\text { suppressed HCC progression in vivo [40] }\end{array}$ \\
\hline DCA & $\begin{array}{c}\text { PDK1 } \\
\text { (mitochondrial activity) }\end{array}$ & Sorafenib (TKI) & $\begin{array}{l}\text { Promoted apoptosis and induced oxidative } \\
\text { stress in vitro and suppress HCC progression } \\
\text { in vivo [61] }\end{array}$ \\
\hline NCT-503 & $\begin{array}{l}\text { PHGDH } \\
\quad(\mathrm{SSP})\end{array}$ & $\begin{array}{l}\text { Sorafenib, Regorafenib and } \\
\text { Lenvatinib (TKIs) }\end{array}$ & $\begin{array}{l}\text { Promoted apoptosis and induced oxidative } \\
\text { stress in vitro and suppressed HCC } \\
\text { progression in vivo [65] }\end{array}$ \\
\hline POM-1 & $\begin{array}{c}\text { CD39L1 } \\
\text { (adenosinergic metabolism) }\end{array}$ & $\begin{array}{l}\text { Anti-PD-1 and anti-CTLA-4 } \\
\text { antibodies (ICIs) }\end{array}$ & $\begin{array}{l}\text { Promoted lymphocyte infiltration and } \\
\text { suppressed HCC progression in vivo [58] }\end{array}$ \\
\hline
\end{tabular}

\subsubsection{HIF-Mediated Induction of Glucose Metabolism under Hypoxia and ICI Resistance}

Intense nutrient competition, including glucose, between hypoxic cancer cells and anti-tumor immune cells, which both have high demand for glucose, is a common phenomenon in HCC that contributes to ICI resistance. Cancer cells often outcompete immune cells for glucose [66]. Cancer cells deplete glucose in the tumor and glucose level at TME is 3-10 times lower than that of normal tissues [67]. GLUT1 expression was highly upregulated in activated T cells and NK cells $[68,69]$. These anti-tumoral immune cells have high glucose demand to fuel glycolysis for their cytotoxicity $[68,70]$. Therefore, glucose-deprived TME is immune suppressive. $\mathrm{CD}^{+} \mathrm{T}$ cells isolated from highly glycolytic tumors with low glucose availability at TME had significantly lower rate of glycolysis, produced significantly less interferon gamma (IFN $\gamma$ ) and these exhaustive phenotypes were associated with faster tumor progression [66]. Recently, exhausted T cells were further categorized into progenitor exhausted T cells and terminally exhausted T cells, as defined as PD1+TIM3-TCF1+ and PD1+TIM3+TCF1- T cells respectively [71]. Interestingly, it has been recently shown that hypoxia drove the differentiation of mouse progenitor exhausted $\mathrm{T}$ cells to terminally exhausted T cells in vitro [72]. While these two subsets of exhausted T cells await further characterization in HCC, another emerging question that merits further exploration is whether hypoxia drives exhausted T cell differentiation through HIF-mediated transcription of genes or hypoxia-induced metabolites in T cells. Inhibition of glucose uptake in NK cells greatly impeded their effector function with lower IFN $\gamma$ and granzyme B production as well as disrupted adhesion with target cells for clearance [73]. Since glucose metabolism is important for proper function of $\mathrm{CD}^{+} \mathrm{T}$ cells and NK cells, it is reasonable to speculate that glucose-deprived TME or glycolysis inhibitor is likely to hinder the efficacy of ICIs in HCC. Indeed, 2-DG inhibited T cell and NK cell growth and activity [68,73]. More pre-clinical studies are urgently needed to determine the effectiveness and therapeutic window of glycolysis inhibitors in combination with ICIs in hypoxic HCC. 


\subsection{HIF-Mediated Induction of Lactate Metabolism under Hypoxia}

LDHA, which is responsible for the conversion of pyruvate to lactate, was overexpressed in hypoxic HCC cells in a HIF-1-dependent manner [26] (Figure 3) (Table 1). Excessive intracellular lactate accumulation leads to cytoplasmic acidification, which is deleterious to cell viability. To maintain normal intracellular $\mathrm{pH}$, monocarboxylate transporter 4 (MCT4), a lactate exporter, is induced by both HIF-1 and HIF-2 for extrusion of lactate [41,42] (Figure 3) (Table 1). While lactate level in normal tissues ranges from $1.5-3 \mathrm{mM}$, it surges to $10-30 \mathrm{mM}$ in tumor tissues [74]. Conventionally, lactate was regarded as a metabolic waste. Interestingly, the differential expression of MCT1, responsible for lactate uptake, and MCT4 within a tumor enables metabolic symbiosis between hypoxic cancer cells at tumor core and normoxic cancer cells at tumor periphery [75]. While hypoxic cancer cells preferentially consume glucose and actively secret lactate to the environment by overexpressing MCT4, normoxic cancer cells predominantly overexpress MCT1 to consume the imported lactate, later converted to pyruvate by LDH, to fuel OXPHOS for growth. Inhibition of MCT1 forced normoxic cancer cells to switch from lactate-fueled to glycolysis-dependent OXPHOS, thus depleting glucose from TME and leading to extensive cell death of hypoxic cancer cells, as they relied heavily on glucose [75]. Furthermore, reduced expression of LDHA and MCT4 effectively suppressed growth of hypoxic tumor in vivo [76,77]. Overexpression of LDHA and MCT4 were frequently found in human HCC with poor clinical outcomes, and LDHA and MCT4 may serve as independent diagnostic biomarkers in HCC $[20,43]$.

\section{HIF-Mediated Induction of Lactate Metabolism and ICI Resistance}

Exogenous lactate increased PD-L1 expression in lung cancer cells that was mediated via lactate receptor, G protein-coupled receptor 81 (GPR81) [78] (Figure 4). Knockdown of GPR81 significantly inhibited lactate-induced PD-L1 expression [78]. Lactate-activated GPR81 contributed to nuclear translocation of a transcriptional coactivator, WW domain containing transcription regulator (TAZ), which then forms a complex with transcriptional enhanced associate domain (TEAD), a transcription factor that promotes PD-L1 expression [78].

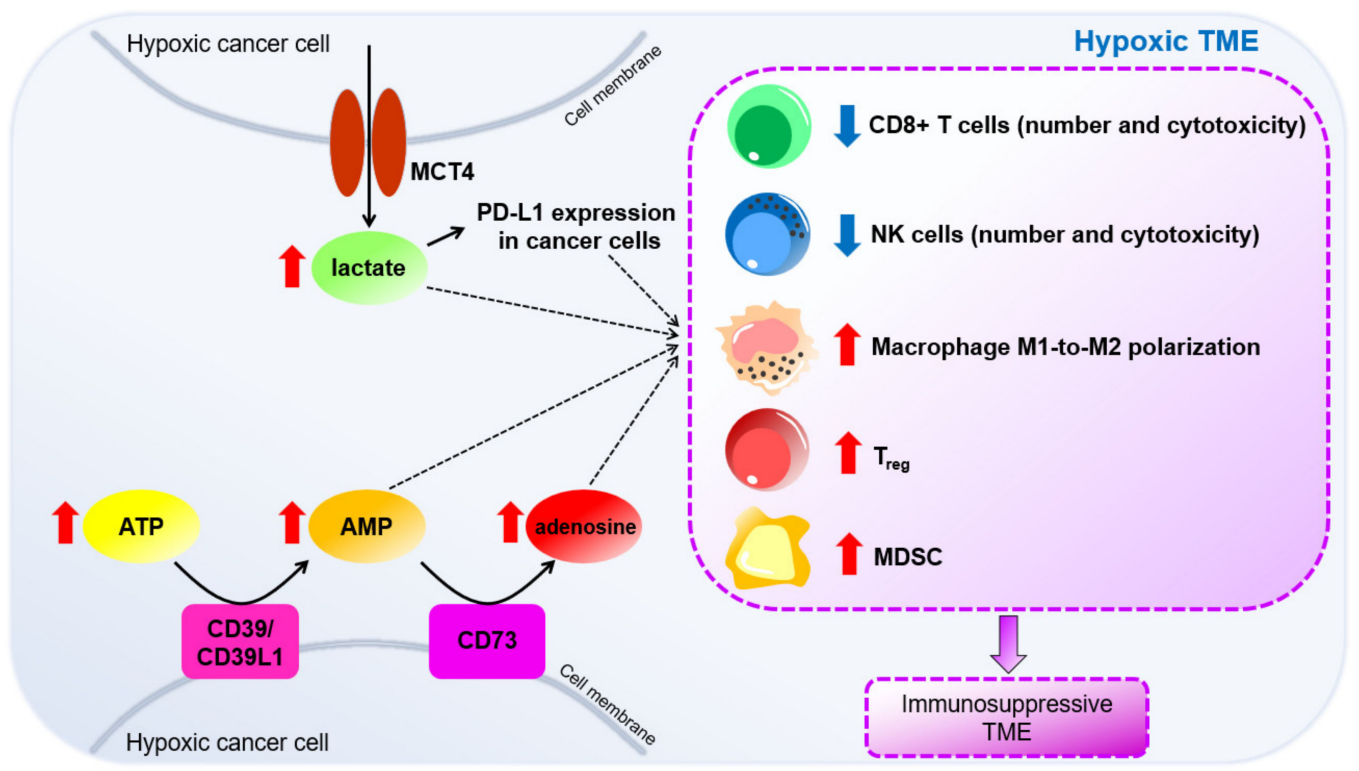

Figure 4. HIF-induced metabolic reprogramming under hypoxia creates an immunosuppressive TME. HIF-mediated induction of lactate metabolism and adenosinergic metabolism leads to the accumulation of oncometabolites, including lactate, adenosine monophosphate (AMP) and adenosine at TME that inhibits anti-tumoral immune cells and promotes expansion of protumoral immune cells, resulting in an immunosuppressive TME that aids immune evasion of tumor cells. 
In $\mathrm{CD}^{+} \mathrm{T}$ cells, lactate induced apoptosis, inhibited proliferation, decreased IFN $\gamma$ production, intracellular perforin and granzyme-B levels [79] (Figure 4). High lactate level at TME inhibited lactate efflux and promoted lactate influx, leading to the accumulation of cytoplasmic lactate, causing intracellular acidification and reduction of $\mathrm{CD}^{+} \mathrm{T}$ cell viability [79]. Removal of lactate from culture medium significantly restored cytokine production and cytotoxicity of $\mathrm{CD}^{+} \mathrm{T}$ cells [79], suggesting that lactate hindered proper function of $\mathrm{CD}^{+} \mathrm{T}$ cells. Similarly, lactate induced apoptosis, reduced perforin, granzyme $B$ production and suppressed expression of activating receptor, NKp46, in NK cells [80] (Figure 4). Lactate-treated NK cells also exhibited intracellular acidification [80]. Additionally, in mice tumor associated macrophage, lactate promoted a shift from anti-tumoral M1 phenotype to protumoral M2 phenotype in a HIF-1-dependent manner [81] (Figure 4). Moreover, lactate induced other M2 markers, including CD206 and CCL17, by activating G protein-coupled receptor 132 (Gpr132) responsible for extracellular lactate sensing [82]. Importantly, only lactate, but not low $\mathrm{pH}$ or $\mathrm{M} 2$ macrophage activating cytokine, IL-4, activated Gpr132 signaling to promote M1-to-M2 switch in macrophage [82]. M2 polarization was abrogated upon removal of lactate from culture medium [82]. Progression of cancer with high lactate content was significantly halted in Gpr132 knockout mice with reduced tumor-associated M2 macrophages, indicating the importance of lactate/Gpr132 axis in inducing M2 macrophages [82]. Moreover, lactate increased the proportion of intratumoral immunosuppressive cells, Treg and MDSCs [83,84] (Figure 4). Interestingly, intratumoral Treg overexpressed MCT1 to take up lactate from TME to sustain OXPHOS [85]. Treg with MCT1 deletion had reduced lactate uptake and lower proliferation rate in melanoma tumors [85]. Treatment of MCT inhibitors blocked lactate export by cancer cells and these inhibitors synergized with anti-PD-1 therapy to profoundly promote IFN $\gamma$ production by $\mathrm{CD}^{+} \mathrm{T}$ cells, thereby reducing tumor burden [86]. Notably, MCT inhibition did not affect viability and effector function of T cells. MCT1 deletion in Treg synergized with anti-PD-1 antibodies to promote tumor regression and significantly increased the survival of tumorbearing mice [85]. Moreover, knockout of LDHA ameliorated the efficacy of anti-PD-1 antibodies to markedly increase infiltrated $\mathrm{CD}^{+} \mathrm{T}$ cells and NK cells and reduced Treg in a melanoma mouse model [87], suggesting the potential of targeting lactate metabolism to improve the effectiveness of ICIs in hypoxic tumors.

\subsection{HIF-Mediated Suppression of Mitochondrial Metabolism under Hypoxia}

Mitochondrial activities are suppressed to prevent excessive ROS accumulation under hypoxia. HIF-1 upregulated PDK1 in hypoxic cancer cells (Table 1) [44,45]. PDK1 inactivates (pyruvate dehydrogenase) PDH enzyme complex, thereby inhibiting the conversion of pyruvate to acetyl-CoA, the substrate of TCA cycle [24,25] (Figure 3). Knockdown of PDK1 led to reduction of pyruvate, but increased levels of TCA intermediates under hypoxia, consolidating the role of PDK1 as a negative regulator of TCA cycle [88]. Loss of PDK1 increased mitochondrial $\mathrm{O}_{2}$ consumption and induced apoptosis especially under hypoxia $[44,45,89]$, whereas overexpression of PDK1 promoted PDH E1 $\alpha$ subunit phosphorylation and rescued survival of HIF-1 $\alpha$ knockout cells cultured under hypoxia [44]. Furthermore, HIF-1 elicited a switch of ECT complex I subunit from NADH dehydrogenase (ubiquinone) 1 alpha subcomplex 4 (NDUFA) to NADH dehydrogenase (ubiquinone) 1 alpha subcomplex 4-like 2 (NDUFA4L2), a less active subunit, to decelerate electron transfer and attenuate ROS production in HCC [46,90] (Figure 3) (Table 1). Knockdown of NDUFA4L2 suppressed HCC tumor growth and lung metastasis [46]. These tumors also had higher oxidative stress, indicating the importance of NDUFA4L2 in lowering ROS in hypoxic HCC. Similarly, HIF-1 modulated a switch from cytochrome C oxidase subunit IV isoform 1 (COX4-1) to COX4-2, a less active subunit in ETC complex IV to prevent excessive ROS accumulation under hypoxia [47] (Figure 3) (Table 1). HIF-1 simultaneously upregulated COX4-2 and mitochondrial protease LON peptidase, which degrades COX4-1 subunit [47]. Both knockdown of COX4-2 and overexpression of COX4-1 induced oxidative stress in hypoxic cancer cells [47]. Moreover, HIF-1 induced miR-210, which 
suppresses iron-sulfur cluster assembly enzyme 1/2 (ISCU1/2) in complex I and III to reduce mitochondrial activity and ROS production under hypoxia [48] (Table 1). Clinically, overexpression of PDK1, NDUFA4L2 and miR-210, as well as the downregulation of COX4-1 were correlated with poor overall survival of HCC patients $[46,50,51,91]$.

Mitochondrial biogenesis is also suppressed in HCC cells under hypoxic stress. HIF1 induced hes related family BHLH transcription factor with YRPW motif 1 (HEY1), a transcriptional repressor in the Notch signal pathway, that downregulate PTEN induced kinase 1 (PINK1) essential for mitochondrial biogenesis (Table 1) [49]. HEY1 overexpression or PINK1 knockdown reduced mitochondrial mass, mitochondrial cristae structure and ROS level in hypoxic HCC cells [49]. In vivo, HEY1 overexpression or PINK1 knockdown consistently promoted HCC growth, demonstrating the protumoral effect of the HIF-1/HEY1/PINK1 axis in hypoxic HCC [49]. Moreover, HIF-1 suppressed MYC protooncogene, BHLH transcription factor (c-MYC) signaling, which had been implicated for mitochondrial biogenesis. HIF-1-induces MAX-interacting protein 1 (MXI-1), which competes with MAX for binding with c-MYC to repress c-MYC activity, in hypoxic cancer cells (Table 1) [52]. While MYC-MAX heterodimers transcriptionally activate target genes, MYCMXI results in transcription repression. Consequently, peroxisome proliferator-activated receptor $\gamma$ coactivator $1 \beta$ (PGC-1 $\beta$ ), a c-MYC target important for mitochondrial biogenesis, was downregulated to lower mitochondrial activity and ROS level [52]. Overexpression of HEY1, downregulation of PINK1 and PGC- $1 \beta$ expression were commonly found in HCC patients $[49,92]$.

HIF-Mediated Suppression of Mitochondrial Metabolism under Hypoxia and TKI Resistance

HIFs suppressed mitochondrial metabolism to limit ROS production under hypoxia. Importantly, Sorafenib induced ROS in HCC cells $[29,93]$. Antioxidant treatment partially rescued cell death upon Sorafenib treatment, suggesting that Sorafenib induced cell death at least partially by inducing oxidative stress. Sorafenib treatment also elevated serum level of advanced oxidation protein products (AOPP), a marker of oxidative stress, in HCC patients [29]. Notably, Sorafenib-treated HCC patients with high AOPP manifested better drug response and survival benefits [29]. It is reasonable to speculate that HIF-mediated suppression of mitochondrial metabolism contributes to Sorafenib resistance by lowering ROS in drug-treated hypoxic HCC. High mitochondrial activity sensitized multiple HCC cell lines to Sorafenib treatment [61]. PDK1 reduces the rate of TCA cycle to prevent ROS accumulation in hypoxic cancer cells. Dichloroacetate (DCA), a PDK inhibitor, greatly sensitized HCC cells to Sorafenib treatment (Table 2) [61].

\subsection{HIF-Mediated Induction of Serine Metabolism under Hypoxia}

In SSP, glucose-derived 3PG, is converted into serine via a three-step enzymatic reaction catalyzed by phosphoglycerate dehydrogenase (PHGDH), phosphoserine aminotransferase 1 (PSAT1) and phosphoserine phosphatase (PSPH). Serine is the substrate of folate cycle, which generates a key antioxidant, NADPH. Serine hydroxymethyltransferase 2 (SHMT2) first converts serine and tetrahydrofolate (THF) to glycine and methylene tetrahydrofolate (MTHF). Other enzymes in the folate cycle include methylenetetrahydrofolate dehydrogenase (NADP+ dependent) 2 (MTHFD2), MTHFD1L and aldehyde dehydrogenase 1 family member L1/2 (ALDH1L1/2). SSP and its downstream folate cycle are activated under hypoxia in an HIF-dependent manner, producing NADPH to counteract oxidative stress in hypoxic cancer cells [28]. PHGDH and SHMT2 were consistently induced in all six breast cancer cells lines cultured under hypoxia, while PSAT1, PSPH, MTHFD2 and MTHFD1L were induced in most of the cell lines in a HIF-dependent manner (Table 1) [28]. Knockdown or inhibition of PHGDH, the first rate-limiting enzyme in SSP, dramatically reduced the level of NADPH, increased level of mitochondrial ROS and induced more extensive cell death in hypoxia [28,94]. Knockdown of PHGDH reduced the level of serine but led to accumulation of glycolytic metabolites, demonstrating that 3PG from glycolysis was diverted to SSP in hypoxic cancer cells [28]. In vivo, 
PHGDH was overexpressed in hypoxic regions of breast tumors [28]. Tumors derived from $P H G D H$ knockdown cells grew much slower with higher level of mitochondrial ROS [28]. SHMT2 was also induced by HIF-1 under hypoxia in neuroblastoma cells [95]. IHC study revealed a positive correlation between SHMT2 and HIF-1 $\alpha$ protein expression in human neuroblastoma tissues [95]. Knockdown of SHMT2 reduced ${ }^{13} \mathrm{C}$-glycine level in hypoxic neuroblastoma cells labelled with ${ }^{13} \mathrm{C}$-serine, consolidating the function of SHMT2 in converting serine to glycine [95]. SHMT2 knockdown reduced level of NADPH, elevated intracellular ROS and induced apoptosis under hypoxia [95]. Important genes in the SSP and folate cycle, including PHGDH, PSPH, MTHFD2, MTHFD1L and SHMT2, were upregulated in human HCC tissues and their overexpression was associated with poor prognosis in HCC patients [53-56].

HIF-Mediated Induction of Serine Metabolism under Hypoxia and TKI Resistance

Our group employed genome-wide CRISPR/Cas9 knockout library screening and identified $\mathrm{PHGDH}$ as the most crucial gene contributing to Sorafenib resistance in HCC cells [65]. RNA-seq revealed that SSP was activated and PHGDH was significantly overexpressed in the Sorafenib-resistant HCC cell line [65]. Knockdown of PHGDH significantly reduced $\mathrm{NADPH} / \mathrm{NADP}^{+}$ratio, induced intracellular ROS and mitochondrial ROS as well as induced apoptosis in Sorafenib-treated HCC cells [65]. Tumors formed by PHGDH knockdown HCC cells were remarkably more sensitive to Sorafenib [65]. Excitingly, we found that SSP was not only activated by Sorafenib, but also other TKIs, including Regorafenib and Lenvatinib. Regorafenib or Lenvatinib significantly induced expressions of genes in SSP, including PHGDH, PSAT1 and PSPH, in HCC cells [65]. PHGDH inhibitor, NCT-503 synergized with Sorafenib to further promote apoptosis in Sorafenib resistant HCC cells (Table 2) [65]. Notably, administration of antioxidant N-acetyl cysteine (NAC) partially rescued cell death caused by combination treatment [65], indicating that NCT503 sensitized HCC cells to Sorafenib at least partially through inducing oxidative stress. In vivo, combination treatment of NCT-503 with Sorafenib completely suppressed growth of HCC tumors [65]. Astonishingly, apart from Sorafenib, NCT-503 synergized with other HCC TKIs to drastically induce apoptotic HCC cell death (Table 2) [65]. PHGDH is an attractive therapeutic target to overcome TKI resistance in hypoxic HCC. Since SSP fuels the folate cycle to produce antioxidant to counteract ROS in hypoxic tumors, it is worthwhile to explore the potential of genes in the folate cycle as therapeutic targets to re-sensitize TKI-resistant HCC tumors.

\subsection{HIF-Mediated Induction of Adenosinergic Metabolism under Hypoxia}

Hypoxia is associated with a significant increase of ATP level in extracellular space [96]. Extracellular ATP is converted to adenosine by HIF-induced ectoenzymes, CD39/CD39L1 and CD73 (Table 1) [57], leading to the accumulation of adenosine under hypoxia [97] (Figure 4). While the concentration of extracellular adenosine ranges between 10-100 nM in normal tissues, it surges to $9-13 \mu \mathrm{M}$ in hypoxic tumors [98]. Both adenosine monophosphate (AMP) and adenosine are immunosuppressive metabolites. We previously demonstrated that HIF-1 induced CD39L1 to produce more extracellular AMP, which inhibited differentiation of MDSC, leading to the accumulation of immunosuppressive MDSC in hypoxic HCC [58]. Upon conversion of AMP to adenosine by CD73 in tumor cells, adenosine mediates its immunosuppressive effect by binding to adenosine receptors, A2A receptor (A2AR) and A2B receptor (A2BR) on immune cells. CD73 and A2AR reduced viability, cytotoxicity and IFN $\gamma$ expression in tumor-infiltrating NK cells and CD8 ${ }^{+} \mathrm{T}$ cells [99-103]. A2BR signaling was responsible for the enrichment of MDSC and the shift from M1-like to M2-like macrophage [104,105]. Genetic deletion or inhibition of CD39L1, CD73, A2AR or A2BR consistently suppressed tumor growth in vivo, indicating the protumoral role of adenosinergic metabolism and signaling [58,100,101,104]. CD39L1 and CD73 were overexpressed in HCC patients with poor prognosis [58,59]. 
HIF-Mediated Induction of Adenosinergic Metabolism under Hypoxia and ICI Resistance

The immunosuppressive role of adenosinergic signaling provides rationale for combination treatment of drugs targeting adenosine metabolism to overcome ICI resistance in HCC. We showed that CD39L1 inhibitor, POM-1, synergized with ICIs to increase lymphocyte infiltration, suppress tumor growth and promote survival of HCC-bearing mice (Table 2) [58]. Excitingly, anti-CD39 (IPH5201) and anti-CD73 (IPH5301) monoclonal antibodies have recently been developed [106]. Inhibiting CD39 and CD73 by these antibodies effectively repressed AMP- or adenosine-mediated suppression of $\mathrm{CD} 8^{+} \mathrm{T}$ cell proliferation and greatly promoted antitumor immune response in vivo [106]. Anti-CD39 and anti-CD73 antibodies synergized with each other to activate $\mathrm{CD} 8^{+} \mathrm{T}$ cells and promote antitumor immunity by abrogating adenosinergic signaling [106]. Excitingly, combination treatment of anti-CD39 or anti-CD73 antibodies with anti-PD-L1 antibody in subjects with advanced solid tumors is currently undergoing Phase 1 clinical trial (NCT04261075). Inhibitors or antibodies targeting adenosine receptors, A2AR and A2BR will be useful to study whether inhibition of adenosine sensing by intratumoral immune cells can further sensitize hypoxic HCC to ICIs treatment.

\section{Targeting Hypoxic HCC to Overcome Drug Resistance}

HIF-induced metabolic reprograming is one of the major molecular mechanisms that contributes to TKI and ICI resistance in HCC. Inhibitors suppressing HIFs and HIF-induced metabolic genes are attractive candidates to be targeted in combination with TKIs and ICIs in HCC patients. Furthermore, targeting hypoxic HCC cells in a HIF-independent manner represents a new direction for HCC therapeutic intervention to suppress the molecular events elicited by hypoxia. An elegant drug screening identified digoxin, an antitumor HIF-1 inhibitor that suppressed growth and progression of hypoxic tumors, including HCC [107-109]. Another HIF-1 inhibitor, EF24 synergized with Sorafenib to reduce cell viability and promote apoptosis of hypoxia HCC cells in vitro and suppressed HCC growth and lung metastasis in vivo [62]. However, the efficacy of Digoxin and EF24 in human HCC is unknown. Following the discovery of targetable PAS-B domain in HIF-2 $\alpha$, PT2385, an HIF-2 inhibitor, was identified [110]. PT2385 synergized with Sorafenib to inhibit HCC growth in vivo [111]. Nonetheless, as renal cancer cells eventually developed resistance to HIF-2 inhibitors [112], more studies are needed to investigate if resistance to PT2385 will develop in HCC-bearing mice and HCC patients. Two groups reported the tumor suppressive role of HIF- $2 \alpha$ in HCC $[113,114]$. Although the majority of studies confirmed HIF- $2 \alpha$ as an oncogene and a prognostic marker associated with poor prognosis in HCC patients [115-117], further investigation is necessary to reconcile the opposing results. Interestingly, functional screening has identified HIF-independent genes important for hypoxic HCC cell survival, which could be exploited as therapeutic targets. Our group employed genome-wide CRISPR/Cas9 library screening and identified protein-tyrosine phosphatase mitochondrial 1 (PTPMT1) as a crucial metabolic regulator for survival of HCC cells under hypoxia [118]. PTPMT1 synthesizes cardiolipin, which is the major constituent of the mitochondrial inner membrane (MIM), which anchors the ETC complexes to allow efficient electron transfer. Inhibition of PTPMT1 led to excessive electron leakage at the ETC, rendering cell death in hypoxic HCC cells. PTPMT1 inhibitor significantly suppressed growth and progression of hypoxic HCC [118], making it a promising drug for combination treatment to combat drug resistant HCC. Genes that are functionally important for hypoxic cell survival might not necessarily be induced by HIFs therefore could also be attractive therapeutic targets to overcome drug resistance in hypoxic HCC.

\section{Conclusions}

Hypoxia is an important component of the TME in HCC. Hypoxia elicits metabolic alterations via HIFs which contribute to resistance of existing HCC therapies, leading to dismal therapeutic outcomes. Overcoming drug resistance in hypoxic HCC is a high priority to ameliorate quality of patients' lives. Targeting genes in metabolic pathways 
that are rewired under hypoxia opens new hope to overcome drug resistance in HCC. While most studies investigated the roles of metabolic reprogramming under hypoxia in conferring Sorafenib resistance, there is a lack of knowledge whether these metabolic rewiring also contribute to resistance of other FDA-approved TKIs for HCC, including Lenventinib, Cabozantinib, Regorafenib and Ramucirumab. It also remains elusive whether inhibitors that target metabolic genes that are induced by HIFs under hypoxia can synergize with other TKIs, apart from Sorafenib, to increase their therapeutic benefits in treating HCC. Furthermore, more preclinical studies are urgently needed to study whether targeting HIF-induced lactate and adenosine metabolism can ameliorate the efficacy and response rate of ICIs in HCC models. However, the potential side effects of metabolic inhibitors to metabolism and cytotoxicity of anti-tumoral immune cells should be carefully evaluated to determine an appropriate therapeutic window of combination treatment with ICIs to combat hypoxic HCC. More translational efforts are warranted to evaluate the efficacy of combining different inhibitors targeting HIF-induced metabolic genes with TKIs or ICIs to overcome drug resistance in HCC patients.

Author Contributions: Conceptualization, writing-original draft preparation and writing-review and editing, C.C.-L.W. and M.H.-R.B. Supervision and funding acquisition, C.C.-L.W. All authors have read and agreed to the published version of the manuscript.

Funding: This work is funded by the Program for Guangdong Introducing Innovative and Entrepreneurial Teams (2019BT02Y198), the InnoHealth-Center for Oncology and Immunology, Croucher Innovation Award, and University of Hong Kong Outstanding Young Researcher Award.

Institutional Review Board Statement: Not applicable.

Informed Consent Statement: Not applicable.

Data Availability Statement: Not applicable.

Conflicts of Interest: The authors declare no conflict of interest.

\section{Abbreviations}

A2A receptor (A2AR); acetyl coenzyme A (acetyl-CoA); adenosine monophosphate (AMP); adenosine triphosphate (ATP); advanced oxidation protein products (AOPP); aldehyde dehydrogenase 1 family member L1 (ALDH1L1); aldolase (ALD); arterial chemoembolization (TACE); arterial embolization transcatheter (TAE); carbonic anhydrase 9 (CA9); clustered regularly interspaced short palindromic repeats (CRISPR); CRISPR associated protein 9 (Cas9); cytochrome C oxidase (COX4); Dichloroacetate (DCA); electron transport chain (ETC); enolase 1 (ENO1); fibroblast growth factor (FGF); flavin adenine dinucleotide (FADH2); fluorodeoxyglucose (FDG); Food and Drug Administration (FDA); glucose transporter type 1 (GLUT1); glucose transporter type 3 (GLUT3); G proteincoupled receptor (GPR); glyceraldehyde-3-phosphate dehydrogenase (GAPDH); hepatocellular carcinoma (HCC); hes related family BHLH transcription factor with YRPW motif 1 (HEY1); hexokinase 2 (HK2); hypoxia-inducible factor (HIF); immune checkpoint inhibitors (ICIs); interferon gamma (IFN $\gamma$ ); iron-sulfur cluster assembly enzyme (ISCU); lactate dehydrogenase A (LDHA); MAX-interacting protein 1 (MXI-1); median partial pressure of $\mathrm{O}_{2}\left(\mathrm{pO}_{2}\right)$; methylene tetrahydrofolate (MTHF); methylenetetrahydrofolate dehydrogenase (NADP+ dependent) 1 like (MTHFD1L); methylenetetrahydrofolate dehydrogenase (NADP+ dependent) 2,(MTHFD2); microRNA-210 (miR-210); mitochondrial inner membrane (MIM); monocarboxylate transporter (MCT); MYC proto-oncogene, BHLH transcription factor (c-Myc); myeloid-derived suppressor cells (MDSC); $\mathrm{N}$-acetyl cysteine (NAC); nicotinamide adenine dinucleotide phosphate (NADPH); NADH dehydrogenase (ubiquinone) 1 alpha subcomplex 4 (NDUFA); natural killer (NK); NADH dehydrogenase (ubiquinone) 1 alpha subcomplex 4-like 2 (NDUFA4L2); nicotinamide adenine dinucleotide (NADH); oxidative phosphorylation (OXPHOS); peroxisome proliferator-activated receptor $\gamma$ coactivator $1 \beta$ (PGC-1 $\beta$ ); phosphofructokinase, liver type (PFKL); phosphoglycerate dehydrogenase (PHGDH); phosphoglycerate kinase 1 (PGK1); phosphoserine aminotransferase 1 (PSAT1); phosphoserine phosphatase (PSPH); platelet-derived growth factor (PDGF); protein tyrosine phosphatase mitochondrial 1 (PTPMT1); PTEN induced kinase 1 (PINK1); pyruvate dehydrogenase (PDH); pyruvate dehydrogenase kinase 1 (PDK1); pyruvate kinase 
M1/2 (PKM); reactive oxygen species (ROS); regulatory T cells (Treg); serine hydroxymethyltransferase 2 (SHMT2); serine synthesis pathway (SSP); solute carrier family 2 member 1 (SLC2A1); solute carrier family 2 member 3 (SLC2A3); tetrahydrofolate (THF); transcriptional enhanced associate domain (TEAD); tricarboxylic acid cycle (TCA); triosephosphate isomerase 1 (TPI1); tumor microenvironment (TME); tyrosine kinase inhibitor (TKI); vascular endothelial growth factor (VEGF); WW domain containing transcription regulator 1 (TAZ); 2-Deoxyglucose (2-DG); 3-bromopyruvate (3-BP); 3-phosphoglyceric acid (3PG).

\section{References}

1. Bray, F.; Ferlay, J.; Soerjomataram, I.; Siegel, R.L.; Torre, L.A.; Jemal, A. Global cancer statistics 2018: GLOBOCAN estimates of incidence and mortality worldwide for 36 cancers in 185 countries. CA Cancer J. Clin. 2018, 68, 394-424. [CrossRef]

2. Chen, C.; Lou, T. Hypoxia inducible factors in hepatocellular carcinoma. Oncotarget 2017, 8, 46691-46703. [CrossRef]

3. Li, J.-Q.; Wu, X.; Gan, L.; Yang, X.-L.; Miao, Z.-H. Hypoxia induces universal but differential drug resistance and impairs anticancer mechanisms of 5-fluorouracil in hepatoma cells. Acta Pharmacol. Sin. 2017, 38, 1642-1654. [CrossRef]

4. Llovet, J.M.; Ricci, S.; Mazzaferro, V.; Hilgard, P.; Gane, E.; Blanc, J.F.; De Oliveira, A.C.; Santoro, A.; Raoul, J.L.; Forner, A.; et al. Sorafenib in Advanced Hepatocellular Carcinoma. N. Engl. J. Med. 2008, 359, 378-390. [CrossRef]

5. $\quad$ Cheng, A.-L.; Kang, Y.-K.; Chen, Z.; Tsao, C.-J.; Qin, S.; Kim, J.S.; Luo, R.; Feng, J.; Ye, S.; Yang, T.-S.; et al. Efficacy and safety of sorafenib in patients in the Asia-Pacific region with advanced hepatocellular carcinoma: A phase III randomised, double-blind, placebo-controlled trial. Lancet Oncol. 2009, 10, 25-34. [CrossRef]

6. Copur, M.S. Sorafenib in advanced hepatocellular carcinoma. N. Engl. J. Med. 2008, 359, 2498, author reply 2498-2499.

7. Ikeda, M.; Okusaka, T.; Mitsunaga, S.; Ueno, H.; Tamai, T.; Suzuki, T.; Hayato, S.; Kadowaki, T.; Okita, K.; Kumada, H. Safety and Pharmacokinetics of Lenvatinib in Patients with Advanced Hepatocellular Carcinoma. Clin. Cancer Res. 2015, 22, 1385-1394. [CrossRef] [PubMed]

8. Abou-Alfa, G.K.; Meyer, T.; Cheng, A.-L.; El-Khoueiry, A.B.; Rimassa, L.; Ryoo, B.-Y.; Cicin, I.; Merle, P.; Chen, Y.; Park, J.W.; et al. Cabozantinib in Patients with Advanced and Progressing Hepatocellular Carcinoma. N. Engl. J. Med. 2018, $379,54-63$. [CrossRef] [PubMed]

9. El-Khoueiry, A.B.; Sangro, B.; Yau, T.C.C.; Crocenzi, T.S.; Kudo, M.; Hsu, C.; Kim, T.-Y.; Choo, S.-P.; Trojan, J.; Welling, T.H.; et al. Nivolumab in patients with advanced hepatocellular carcinoma (CheckMate 040): An open-label, non-comparative, phase $1 / 2$ dose escalation and expansion trial. Lancet 2017, 389, 2492-2502. [CrossRef]

10. Zhu, A.X.; Kang, Y.-K.; Yen, C.-J.; Finn, R.S.; Galle, P.R.; Llovet, J.M.; Assenat, E.; Brandi, G.; Pracht, M.; Lim, H.Y.; et al. Ramucirumab after sorafenib in patients with advanced hepatocellular carcinoma and increased $\alpha$-fetoprotein concentrations (REACH-2): A randomised, double-blind, placebo-controlled, phase 3 trial. Lancet Oncol. 2019, 20, 282-296. [CrossRef]

11. Shi, F.; Shi, M.; Zeng, Z.; Qi, R.-Z.; Liu, Z.-W.; Zhang, J.-Y.; Yang, Y.-P.; Tien, P.; Wang, F.-S. PD-1 and PD-L1 upregulation promotes CD8+ T-cell apoptosis and postoperative recurrence in hepatocellular carcinoma patients. Int. J. Cancer 2010, 128, 887-896. [CrossRef]

12. Pesce, S.; Greppi, M.; Grossi, F.; Del Zotto, G.; Moretta, L.; Sivori, S.; Genova, C.; Marcenaro, E. PD/1-PD-Ls Checkpoint: Insight on the Potential Role of NK Cells. Front. Immunol. 2019, 10, 1242. [CrossRef] [PubMed]

13. Parry, R.V.; Chemnitz, J.M.; Frauwirth, K.A.; Lanfranco, A.R.; Braunstein, I.; Kobayashi, S.V.; Linsley, P.S.; Thompson, C.B.; Riley, J.L. CTLA-4 and PD-1 Receptors Inhibit T-Cell Activation by Distinct Mechanisms. Mol. Cell. Biol. 2005, 25, $9543-9553$. [CrossRef] [PubMed]

14. McKeown, S.R. Defining normoxia, physoxia and hypoxia in tumours-implications for treatment response. Br. J. Radiol. 2014, 87, 20130676. [CrossRef]

15. Vaupel, P.; Höckel, M.; Mayer, A. Detection and Characterization of Tumor Hypoxia Using $\mathrm{pO}_{2}$ Histography. Antioxid. Redox Signal. 2007, 9, 1221-1236. [CrossRef] [PubMed]

16. Liu, X.-B.; Cheng, Q.; Geng, W.; Ling, C.-C.; Liu, Y.; Ng, K.T.-P.; Yam, J.W.P.; Guan, X.-Y.; Lo, C.-M.; Man, K. Enhancement of cisplatin-based TACE by a hemoglobin-based oxygen carrier in an orthotopic rat HCC model. Artif. Cells Nanomed. Biotechnol. 2013, 42, 229-236. [CrossRef] [PubMed]

17. Riedl, C.C.; Brader, P.; Zanzonico, P.B.; Chun, Y.S.; Woo, Y.; Singh, P.; Carlin, S.; Wen, B.; Ling, C.C.; Hricak, H.; et al. Imaging Hypoxia in Orthotopic Rat Liver Tumors with Iodine 124-labeled Iodoazomycin Galactopyranoside PET. Radiology 2008, 248, 561-570. [CrossRef]

18. Wada, H.; Nagano, H.; Yamamoto, H.; Yang, Y.; Kondo, M.; Ota, H.; Nakamura, M.; Yoshioka, S.; Kato, H.; Damdinsuren, B.; et al. Expression pattern of angiogenic factors and prognosis after hepatic resection in hepatocellular carcinoma: Importance of angiopoietin-2 and hypoxia-induced factor-1a. Liver Int. 2006, 26, 414-423. [CrossRef]

19. Amann, T.; Maegdefrau, U.; Hartmann, A.; Agaimy, A.; Marienhagen, J.; Weiss, T.; Stoeltzing, O.; Warnecke, C.; Schölmerich, J.; Oefner, P.J.; et al. GLUT1 Expression Is Increased in Hepatocellular Carcinoma and Promotes Tumorigenesis. Am. J. Pathol. 2009, 174, 1544-1552. [CrossRef]

20. Guo, Y.; Li, X.; Sun, X.; Wang, J.; Yang, X.; Zhou, X.; Liu, X.; Liu, W.; Yuan, J.; Yao, L.; et al. Combined Aberrant Expression of NDRG2 and LDHA Predicts Hepatocellular Carcinoma Prognosis and Mediates the Anti-tumor Effect of Gemcitabine. Int. J. Biol. Sci. 2019, 15, 1771-1786. [CrossRef] 
21. Huang, W.-J.; Jeng, Y.-M.; Lai, H.-S.; Fong, I.-U.; Sheu, F.-Y.B.; Lai, P.-L.; Yuan, R.-H. Expression of Hypoxic Marker Carbonic Anhydrase IX Predicts Poor Prognosis in Resectable Hepatocellular Carcinoma. PLoS ONE 2015, 10, e0119181. [CrossRef] [PubMed]

22. Helmlinger, G.; Yuan, F.; Dellian, M.; Jain, R.K. Interstitial pH and pO2 gradients in solid tumors in vivo: High-resolution measurements reveal a lack of correlation. Nat. Med. 1997, 3, 177-182. [CrossRef]

23. Sun, X.; Jiang, H.; Jiang, X.; Tan, H.; Meng, Q.; Sun, B.; Xu, R.; Krissansen, G.W. Antisense Hypoxia-Inducible Factor-1 $\alpha$ Augments Transcatheter Arterial Embolization in the Treatment of Hepatocellular Carcinomas in Rats. Hum. Gene Ther. 2009, 20, 314-324. [CrossRef] [PubMed]

24. Korotchkina, L.G.; Patel, M.S. Site Specificity of Four Pyruvate Dehydrogenase Kinase Isoenzymes toward the Three Phosphorylation Sites of Human Pyruvate Dehydrogenase. J. Biol. Chem. 2001, 276, 37223-37229. [CrossRef]

25. Korotchkina, L.G.; Patel, M.S. Mutagenesis Studies of the Phosphorylation Sites of Recombinant Human Pyruvate Dehydrogenase. SITE-SPECIFIC REGULATION. J. Biol. Chem. 1995, 270, 14297-14304. [CrossRef]

26. Ma, L.; Li, G.; Zhu, H.; Dong, X.; Zhao, D.; Jiang, X.; Li, J.; Qiao, H.; Ni, S.; Sun, X. 2-Methoxyestradiol synergizes with sorafenib to suppress hepatocellular carcinoma by simultaneously dysregulating hypoxia-inducible factor-1 and -2. Cancer Lett. 2014, 355, 96-105. [CrossRef] [PubMed]

27. Semenza, G.L. Hypoxia-Inducible Factors in Physiology and Medicine. Cell 2012, 148, 399-408. [CrossRef] [PubMed]

28. Samanta, D.; Park, Y.; Andrabi, S.A.; Shelton, L.M.; Gilkes, D.M.; Semenza, G.L. PHGDH Expression Is Required for Mitochondrial Redox Homeostasis, Breast Cancer Stem Cell Maintenance, and Lung Metastasis. Cancer Res. 2016, 76, 4430-4442. [CrossRef]

29. Coriat, R.; Nicco, C.; Chéreau, C.; Mir, O.; Alexandre, J.; Ropert, S.; Weill, B.; Chaussade, S.; Goldwasser, F.; Batteux, F. Sorafenib-Induced Hepatocellular Carcinoma Cell Death Depends on Reactive Oxygen Species Production In Vitro and In Vivo. Mol. Cancer Ther. 2012, 11, 2284-2293. [CrossRef] [PubMed]

30. Iyer, N.V.; Kotch, L.E.; Agani, F.; Leung, S.W.; Laughner, E.; Wenger, R.H.; Gassmann, M.; Gearhart, J.D.; Lawler, A.M.; Yu, A.Y; et al. Cellular and developmental control of O2 homeostasis by hypoxia-inducible factor 1alpha. Genes Dev. 1998, 12, 149-162. [CrossRef] [PubMed]

31. Clavo, A.C.; Brown, R.S.; Wahl, R.L.; Clavo, A.C.; Brown, R.S.; Wahl, R.L. Fluorodeoxyglucose uptake in human cancer cell lines is increased by hypoxia. J. Nucl. Med. 1995, 36, 1625-1632.

32. Xia, H.; Chen, J.; Gao, H.; Kong, S.N.; Deivasigamani, A.; Shi, M.; Xie, T.; Hui, K.M. Hypoxia-induced modulation of glucose transporter expression impacts 18F-fluorodeoxyglucose PET-CT imaging in hepatocellular carcinoma. Eur. J. Nucl. Med. Mol. Imaging 2019, 47, 787-797. [CrossRef]

33. Pedersen, P.L.; Mathupala, S.; Rempel, A.; Geschwind, J.; Ko, Y.H. Mitochondrial bound type II hexokinase: A key player in the growth and survival of many cancers and an ideal prospect for therapeutic intervention. Biochim. Biophys. Acta (BBA) Bioenerg. 2002, 1555, 14-20. [CrossRef]

34. Gwak, G.-Y.; Yoon, J.-H.; Kim, K.M.; Lee, H.-S.; Chung, J.W.; Gores, G.J. Hypoxia stimulates proliferation of human hepatoma cells through the induction of hexokinase II expression. J. Hepatol. 2005, 42, 358-364. [CrossRef]

35. Guo, W.; Qiu, Z.; Wang, Z.; Wang, Q.; Tan, N.; Chen, T.; Chen, Z.; Huang, S.; Gu, J.; Li, J.; et al. MiR-199a-5p is negatively associated with malignancies and regulates glycolysis and lactate production by targeting hexokinase 2 in liver cancer. Hepatology 2015, 62, 1132-1144. [CrossRef]

36. Gao, H.; Hao, Y.; Zhou, X.; Li, H.; Liu, F.; Zhu, H.; Song, X.; Niu, Z.; Ni, Q.; Chen, M.; et al. Prognostic value of glucose transporter 3 expression in hepatocellular carcinoma. Oncol. Lett. 2019, 19, 691-699. [CrossRef]

37. Li, X.; Jiang, F.; Ge, Z.; Chen, B.; Yu, J.; Xin, M.; Wang, J.; An, L.; Wei, J.; Wu, L. Fructose-Bisphosphate Aldolase A Regulates Hypoxic Adaptation in Hepatocellular Carcinoma and Involved with Tumor Malignancy. Dig. Dis. Sci. 2019, 64, 3215-3227. [CrossRef] [PubMed]

38. Ganapathy-Kanniappan, S.; Kunjithapatham, R.; Geschwind, J.-F. Glyceraldehyde-3-Phosphate Dehydrogenase: A Promising Target for Molecular Therapy in Hepatocellular Carcinoma. Oncotarget 2012, 3, 940-953. [CrossRef] [PubMed]

39. Zhang, Z.-F.; Feng, X.-S.; Chen, H.; Duan, Z.-J.; Wang, L.-X.; Yang, D.; Liu, P.-X.; Zhang, Q.-P.; Jin, Y.-L.; Sun, Z.-G.; et al. Prognostic significance of synergistic hexokinase-2 and beta2-adrenergic receptor expression in human hepatocelluar carcinoma after curative resection. BMC Gastroenterol. 2016, 16, 1-10. [CrossRef]

40. Yoo, J.-J.; Yu, S.J.; Na, J.; Kim, K.; Cho, Y.Y.; Lee, Y.B.; Cho, E.J.; Lee, J.-H.; Kim, Y.J.; Youn, H.; et al. Hexokinase-II Inhibition Synergistically Augments the Anti-tumor Efficacy of Sorafenib in Hepatocellular Carcinoma. Int. J. Mol. Sci. 2019, $20,1292$. [CrossRef] [PubMed]

41. Schito, L.; Semenza, G.L. Hypoxia-Inducible Factors: Master Regulators of Cancer Progression. Trends Cancer 2016, 2, 758-770. [CrossRef] [PubMed]

42. Cui, X.G.; Han, Z.T.; He, S.H.; Wu, X.D.; Chen, T.R.; Shao, C.H.; Chen, D.L.; Su, N.; Chen, Y.M.; Wang, T.; et al. HIF1/2alpha mediates hypoxia-induced LDHA expression in human pancreatic cancer cells. Oncotarget 2017, 8, 24840-24852. [CrossRef]

43. Chen, H.-L.; Ouyang, H.-Y.; Le, Y.; Jiang, P.; Tang, H.; Yu, Z.-S.; He, M.-K.; Tang, Y.-Q.; Shi, M. Aberrant MCT4 and GLUT1 expression is correlated with early recurrence and poor prognosis of hepatocellular carcinoma after hepatectomy. Cancer Med. 2018, 7, 5339-5350. [CrossRef] [PubMed]

44. Kim, J.-W.; Tchernyshyov, I.; Semenza, G.L.; Dang, C.V. HIF-1-mediated expression of pyruvate dehydrogenase kinase: A metabolic switch required for cellular adaptation to hypoxia. Cell Metab. 2006, 3, 177-185. [CrossRef] [PubMed] 
45. Papandreou, I.; Cairns, R.A.; Fontana, L.; Lim, A.L.; Denko, N.C. HIF-1 mediates adaptation to hypoxia by actively downregulating mitochondrial oxygen consumption. Cell Metab. 2006, 3, 187-197. [CrossRef]

46. Lai, R.K.-H.; Xu, I.M.-J.; Chiu, D.K.-C.; Tse, A.P.-W.; Wei, L.L.; Law, D.C.-T.; Lee, D.; Wong, C.-M.; Wong, M.P.; Ming-Jing, X.I.; et al. NDUFA4L2 Fine-tunes Oxidative Stress in Hepatocellular Carcinoma. Clin. Cancer Res. 2016, 22, 3105-3117. [CrossRef]

47. Fukuda, R.; Zhang, H.; Kim, J.W.; Shimoda, L.; Dang, C.V.; Semenza, G.L. HIF-1 regulates cytochrome oxidase subunits to optimize efficiency of respiration in hypoxic cells. Cell 2007, 129, 111-122. [CrossRef]

48. Chan, S.Y.; Zhang, Y.Y.; Hemann, C.; Mahoney, C.E.; Zweier, J.L.; Loscalzo, J. MicroRNA-210 controls mitochondrial metabolism during hypoxia by repressing the iron-sulfur cluster assembly proteins ISCU1/2. Cell Metab. 2009, 10, 273-284. [CrossRef]

49. Chiu, D.K.-C.; Tse, A.P.-W.; Law, C.-T.; Xu, I.M.-J.; Lee, D.; Chen, M.; Lai, R.K.-H.; Yuen, V.W.-H.; Cheu, J.W.-S.; Ho, D.W.$\mathrm{H}$; et al. Hypoxia regulates the mitochondrial activity of hepatocellular carcinoma cells through HIF/HEY1/PINK1 pathway. Cell Death Dis. 2019, 10,1-16. [CrossRef]

50. Wu, X.; Wang, J.; Liu, F.; Ao, P.; Li, X.; Zheng, H.; Wu, D.; Zhang, N.; She, J.; Yuan, J. Correlation of PDK1 expression with clinicopathologic features and prognosis of hepatocellular carcinoma. OncoTargets Ther. 2016, 9, 5597-5602. [CrossRef] [PubMed]

51. Ji, J.; Rong, Y.; Luo, C.L.; Li, S.; Jiang, X.; Weng, H.; Chen, H.; Zhang, W.W.; Xie, W.; Wang, F.B. Up-Regulation of hsa-miR-210 Promotes Venous Metastasis and Predicts Poor Prognosis in Hepatocellular Carcinoma. Front. Oncol. 2018, 8, 569. [CrossRef]

52. Zhang, H.; Gao, P.; Fukuda, R.; Kumar, G.; Krishnamachary, B.; Zeller, K.I.; Dang, C.V.; Semenza, G.L. HIF-1 inhibits mitochondrial biogenesis and cellular respiration in VHL-deficient renal cell carcinoma by repression of C-MYC activity. Cancer Cell 2007, 11, 407-420. [CrossRef] [PubMed]

53. Liu, S.; Sun, Y.; Jiang, M.; Li, Y.; Tian, Y.; Xue, W.; Ding, N.; Cheng, C.; Li, J.; Miao, X.; et al. Glyceraldehyde-3-phosphate dehydrogenase promotes liver tumorigenesis by modulating phosphoglycerate dehydrogenase. Hepatology 2017, 66, 631-645. [CrossRef] [PubMed]

54. Sun, L.; Song, L.; Wan, Q.; Wu, G.; Li, X.; Wang, Y.; Wang, J.; Liu, Z.; Zhong, X.; He, X.; et al. cMyc-mediated activation of serine biosynthesis pathway is critical for cancer progression under nutrient deprivation conditions. Cell Res. 2015, 25, 429-444. [CrossRef] [PubMed]

55. Liu, X.; Huang, Y.; Jiang, C.; Ou, H.; Guo, B.; Liao, H.; Li, X.; Yang, D. Methylenetetrahydrofolate dehydrogenase 2 overexpression is associated with tumor aggressiveness and poor prognosis in hepatocellular carcinoma. Dig. Liver Dis. 2016, 48, 953-960. [CrossRef] [PubMed]

56. Lee, D.; Xu, I.M.-J.; Chiu, D.K.-C.; Lai, R.K.-H.; Tse, A.P.-W.; Li, L.L.; Law, C.-T.; Tsang, F.H.-C.; Wei, L.L.; Chan, C.Y.-K.; et al. Folate cycle enzyme MTHFD1L confers metabolic advantages in hepatocellular carcinoma. J. Clin. Investig. 2017, 127, 1856-1872. [CrossRef] [PubMed]

57. Li, J.; Wang, L.; Chen, X.; Li, L.; Li, Y.; Ping, Y.; Huang, L.; Yue, D.; Zhang, Z.; Wang, F.; et al. CD39/CD73 upregulation on myeloidderived suppressor cells via TGF-beta-mTOR-HIF-1 signaling in patients with non-small cell lung cancer. Oncoimmunology 2017, 6, e1320011. [CrossRef]

58. Chiu, D.K.-C.; Tse, A.P.-W.; Xu, I.M.-J.; Di Cui, J.; Lai, R.K.-H.; Li, L.L.; Koh, H.-Y.; Tsang, F.H.-C.; Wei, L.L.; Wong, C.-M.; et al. Hypoxia inducible factor HIF-1 promotes myeloid-derived suppressor cells accumulation through ENTPD2/CD39L1 in hepatocellular carcinoma. Nat. Commun. 2017, 8, 517. [CrossRef] [PubMed]

59. Ma, X.L.; Shen, M.N.; Hu, B.; Wang, B.L.; Yang, W.J.; Lv, L.H.; Wang, H.; Zhou, Y.; Jin, A.L.; Sun, Y.F.; et al. CD73 promotes hepatocellular carcinoma progression and metastasis via activating PI3K/AKT signaling by inducing Rap1-mediated membrane localization of P110beta and predicts poor prognosis. J. Hematol. Oncol. 2019, 12, 37. [CrossRef]

60. Cao, X.; Fang, L.; Gibbs, S.; Huang, Y.; Dai, Z.; Wen, P.; Zheng, X.; Sadee, W.; Sun, D. Glucose uptake inhibitor sensitizes cancer cells to daunorubicin and overcomes drug resistance in hypoxia. Cancer Chemother. Pharmacol. 2006, 59, 495-505. [CrossRef]

61. Shen, Y.-C.; Ou, D.-L.; Hsu, C.; Lin, K.-L.; Chang, C.-Y.; Lin, C.-Y.; Liu, S.-H.; Cheng, A.-L. Activating oxidative phosphorylation by a pyruvate dehydrogenase kinase inhibitor overcomes sorafenib resistance of hepatocellular carcinoma. Br. J. Cancer 2012, 108, 72-81. [CrossRef] [PubMed]

62. Liang, Y.; Zheng, T.; Song, R.; Wang, J.; Yin, D.; Wang, L.; Liu, H.; Tian, L.; Fang, X.; Meng, X.; et al. Hypoxia-mediated sorafenib resistance can be overcome by EF24 through Von Hippel-Lindau tumor suppressor-dependent HIF-1 $\alpha$ inhibition in hepatocellular carcinoma. Hepatology 2013, 57, 1847-1857. [CrossRef]

63. Tesori, V.; Piscaglia, A.C.; Samengo, D.; Barba, M.; Bernardini, C.; Scatena, R.; Pontoglio, A.; Castellini, L.; Spelbrink, J.; Maulucci, G.; et al. The multikinase inhibitor Sorafenib enhances glycolysis and synergizes with glycolysis blockade for cancer cell killing Sci. Rep. 2015, 5, 1-9. [CrossRef] [PubMed]

64. Reyes, R.; Wani, N.; Ghoshal, K.; Jacob, S.T.; Motiwala, T. Sorafenib and 2-Deoxyglucose Synergistically Inhibit Proliferation of Both Sorafenib-Sensitive and -Resistant HCC Cells by Inhibiting ATP Production. Gene Expr. 2017, 17, 129-140. [CrossRef]

65. Wei, L.; Lee, D.; Law, C.-T.; Zhang, M.S.; Shen, J.; Chin, D.W.-C.; Zhang, A.; Tsang, F.H.-C.; Wong, C.L.-S.; Ng, I.O.-L.; et al. Genome-wide CRISPR/Cas9 library screening identified PHGDH as a critical driver for Sorafenib resistance in HCC. Nat. Commun. 2019, 10, 1-13. [CrossRef]

66. Chang, C.-H.; Qiu, J.; O'Sullivan, D.; Buck, M.; Noguchi, T.; Curtis, J.D.; Chen, Q.; Gindin, M.; Gubin, M.M.; Van Der Windt, G.J.; et al. Metabolic Competition in the Tumor Microenvironment Is a Driver of Cancer Progression. Cell 2015, 162, 1229-1241. [CrossRef] 
67. Urasaki, Y.; Heath, L.; Xu, C.W. Coupling of Glucose Deprivation with Impaired Histone H2B Monoubiquitination in Tumors. PLoS ONE 2012, 7, e36775. [CrossRef] [PubMed]

68. Cao, Y.; Rathmell, J.C.; MacIntyre, A.N. Metabolic Reprogramming towards Aerobic Glycolysis Correlates with Greater Proliferative Ability and Resistance to Metabolic Inhibition in CD8 versus CD4 T Cells. PLoS ONE 2014, 9, e104104. [CrossRef]

69. Keating, S.E.; Zaiatz-Bittencourt, V.; Loftus, R.M.; Keane, C.; Brennan, K.; Finlay, D.K.; Gardiner, C.M. Metabolic Reprogramming Supports IFN-gamma Production by CD56bright NK Cells. J. Immunol. 2016, 196, 2552-2560. [CrossRef] [PubMed]

70. Wang, Z.; Guan, D.; Wang, S.; Chai, L.Y.A.; Xu, S.; Lam, K.-P. Glycolysis and Oxidative Phosphorylation Play Critical Roles in Natural Killer Cell Receptor-Mediated Natural Killer Cell Functions. Front. Immunol. 2020, 11, 202. [CrossRef]

71. Escobar, G.; Mangani, D.; Anderson, A.C. T cell factor 1: A master regulator of the T cell response in disease. Sci. Immunol. 2020, 5, eabb9726. [CrossRef] [PubMed]

72. Bannoud, N.; Dalotto-Moreno, T.; Kindgard, L.; García, P.A.; Blidner, A.G.; Mariño, K.V.; Rabinovich, G.A.; Croci, D.O. Hypoxia Supports Differentiation of Terminally Exhausted CD8 T Cells. Front. Immunol. 2021, 12, 660944. [CrossRef]

73. Mah-Som, A.; Rashidi, A.; Keppel, M.P.; Saucier, N.; Moore, E.; Alinger, J.B.; Tripathy, S.K.; Agarwal, S.K.; Jeng, E.K.; Wong, H.C.; et al. Glycolytic requirement for NK cell cytotoxicity and cytomegalovirus control. JCI Insight 2017, 2. [CrossRef]

74. DE LA Cruz, K.; Castro-Muñoz, L.J.; Reyes-Hernández, D.O.; García-Carrancá, A.; Manzo-Merino, J. Lactate in the Regulation of Tumor Microenvironment and Therapeutic Approaches. Front. Oncol. 2019, 9, 1143. [CrossRef] [PubMed]

75. Sonveaux, P.; Vegran, F.; Schroeder, T.; Wergin, M.; Verrax, J.; Rabbani, Z.N.; De Saedeleer, C.J.; Kennedy, K.M.; Diepart, C.; Jordan, B.F.; et al. Targeting lactate-fueled respiration selectively kills hypoxic tumor cells in mice. J. Clin. Investig. 2008, 118, 3930-3942. [CrossRef]

76. Sheng, S.L.; Liu, J.J.; Dai, Y.H.; Sun, X.G.; Xiong, X.P.; Huang, G. Knockdown of lactate dehydrogenase A suppresses tumor growth and metastasis of human hepatocellular carcinoma. FEBS J. 2012, 279, 3898-3910. [CrossRef]

77. Lim, K.S.; Lim, K.J.; Price, A.C.; A Orr, B.; Eberhart, C.G.; Bar, E.E. Inhibition of monocarboxylate transporter-4 depletes stem-like glioblastoma cells and inhibits HIF transcriptional response in a lactate-independent manner. Oncogene 2013, 33, 4433-4441. [CrossRef]

78. Feng, J.; Yang, H.; Zhang, Y.; Wei, H.; Zhu, Z.; Zhu, B.; Yang, M.; Cao, W.; Wang, L.; Wu, Z. Tumor cell-derived lactate induces TAZ-dependent upregulation of PD-L1 through GPR81 in human lung cancer cells. Oncogene 2017, 36, 5829-5839. [CrossRef]

79. Fischer, K.; Hoffmann, P.; Völkl, S.; Meidenbauer, N.; Ammer, J.; Edinger, M.; Gottfried, E.; Schwarz, S.; Rothe, G.; Hoves, S.; et al. Inhibitory effect of tumor cell-derived lactic acid on human T cells. Blood 2007, 109, 3812-3819. [CrossRef]

80. Harmon, C.; Robinson, M.W.; Hand, F.; AlMuaili, D.; Mentor, K.; Houlihan, D.D.; Hoti, E.; Lynch, L.; Geoghegan, J.; O’Farrelly, C. Lactate-Mediated Acidification of Tumor Microenvironment Induces Apoptosis of Liver-Resident NK Cells in Colorectal Liver Metastasis. Cancer Immunol. Res. 2018, 7, 335-346. [CrossRef]

81. Colegio, O.R.; Chu, N.-Q.; Szabo, A.L.; Chu, T.; Rhebergen, A.M.; Jairam, V.; Cyrus, N.; Brokowski, C.E.; Eisenbarth, S.C.; Phillips, G.M.; et al. Functional polarization of tumour-associated macrophages by tumour-derived lactic acid. Nature 2014, 513, 559-563. [CrossRef] [PubMed]

82. Chen, P.; Zuo, H.; Xiong, H.; Kolar, M.; Chu, Q.; Saghatelian, A.; Siegwart, D.J.; Wan, Y. Gpr132 sensing of lactate mediates tumor-macrophage interplay to promote breast cancer metastasis. Proc. Natl. Acad. Sci. USA 2017, 114, 580-585. [CrossRef]

83. Comito, G.; Iscaro, A.; Bacci, M.; Morandi, A.; Ippolito, L.; Parri, M.; Montagnani, I.; Raspollini, M.R.; Serni, S.; Simeoni, L.; et al. Lactate modulates CD4+ T-cell polarization and induces an immunosuppressive environment, which sustains prostate carcinoma progression via TLR8/miR21 axis. Oncogene 2019, 38, 3681-3695. [CrossRef] [PubMed]

84. Husain, Z.; Huang, Y.; Seth, P.; Sukhatme, V.P. Tumor-Derived Lactate Modifies Antitumor Immune Response: Effect on Myeloid-Derived Suppressor Cells and NK Cells. J. Immunol. 2013, 191, 1486-1495. [CrossRef] [PubMed]

85. Watson, M.J.; Vignali, P.D.A.; Mullett, S.J.; Overacre-Delgoffe, A.E.; Peralta, R.M.; Grebinoski, S.; Menk, A.V.; Rittenhouse, N.L.; DePeaux, K.; Whetstone, R.D.; et al. Metabolic support of tumour-infiltrating regulatory T cells by lactic acid. Nat. Cell Biol. 2021, 591, 645-651. [CrossRef]

86. Renner, K.; Bruss, C.; Schnell, A.; Koehl, G.; Becker, H.M.; Fante, M.; Menevse, A.-N.; Kauer, N.; Blazquez, R.; Hacker, L.; et al. Restricting Glycolysis Preserves T Cell Effector Functions and Augments Checkpoint Therapy. Cell Rep. 2019, 29, 135-150.e9. [CrossRef]

87. Daneshmandi, S.; Wegiel, B.; Seth, P. Blockade of Lactate Dehydrogenase-A (LDH-A) Improves Efficacy of Anti-Programmed Cell Death-1 (PD-1) Therapy in Melanoma. Cancers 2019, 11, 450. [CrossRef]

88. Dupuy, F.; Tabariès, S.; Andrzejewski, S.; Dong, Z.; Blagih, J.; Annis, M.G.; Omeroglu, A.; Gao, D.; Leung, S.; Amir, E.; et al. PDK1-Dependent Metabolic Reprogramming Dictates Metastatic Potential in Breast Cancer. Cell Metab. 2015, 22, 577-589. [CrossRef] [PubMed]

89. McFate, T.; Mohyeldin, A.; Lu, H.; Thakar, J.; Henriques, J.; Halim, N.D.; Wu, H.; Schell, M.J.; Tsang, T.M.; Teahan, O.; et al. Pyruvate Dehydrogenase Complex Activity Controls Metabolic and Malignant Phenotype in Cancer Cells. J. Biol. Chem. 2008, 283, 22700-22708. [CrossRef]

90. Tello, D.; Balsa, E.; Acosta-Iborra, B.; Fuertes-Yebra, E.; Elorza, A.; Ordóñez, Á.; Corral-Escariz, M.; Soro, I.; Lopez, J.A.; PeralesClemente, E.; et al. Induction of the Mitochondrial NDUFA4L2 Protein by HIF-1 $\alpha$ Decreases Oxygen Consumption by Inhibiting Complex I Activity. Cell Metab. 2011, 14, 768-779. [CrossRef] [PubMed] 
91. Le, P.-H.; Huang, S.-C.; Lim, S.-N.; Chou, C.-H.; Yeh, T.-S.; Chen, T.-C.; Yen, T.-H.; Su, M.-Y.; Chiu, C.-T.; Yeh, C.-T.; et al. Complex IV subunit 1 defect predicts postoperative survival in hepatocellular carcinoma. Oncol. Lett. 2014, 7, 1430-1438. [CrossRef]

92. Li, Y.; Kasim, V.; Yan, X.; Li, L.; Meliala, I.T.S.; Huang, C.; Li, Z.; Lei, K.; Song, G.; Zheng, X.; et al. Yin Yang 1 facilitates hepatocellular carcinoma cell lipid metabolism and tumor progression by inhibiting PGC-1beta-induced fatty acid oxidation. Theranostics 2019, 9, 7599-7615. [CrossRef]

93. Diehn, M.; Cho, R.W.; Lobo, N.A.; Kalisky, T.; Dorie, M.J.; Kulp, A.N.; Qian, D.; Lam, J.S.; Ailles, L.E.; Wong, M.; et al. Association of reactive oxygen species levels and radioresistance in cancer stem cells. Nature 2009, 458, 780-783. [CrossRef] [PubMed]

94. Engel, A.L.; Lorenz, N.I.; Klann, K.; Münch, C.; Depner, C.; Steinbach, J.P.; Ronellenfitsch, M.W.; Luger, A.-L. Serine-dependent redox homeostasis regulates glioblastoma cell survival. Br. J. Cancer 2020, 122, 1391-1398. [CrossRef]

95. Ye, J.; Fan, J.; Venneti, S.; Wan, Y.-W.; Pawel, B.R.; Zhang, J.; Finley, L.W.; Lu, C.; Lindsten, T.; Cross, J.; et al. Serine Catabolism Regulates Mitochondrial Redox Control during Hypoxia. Cancer Discov. 2014, 4, 1406-1417. [CrossRef] [PubMed]

96. To, W.L.; Kumar, P.; Marshall, J. Hypoxia is an effective stimulus for vesicular release of ATP from human umbilical vein endothelial cells. Placenta 2015, 36, 759-766. [CrossRef]

97. Di Virgilio, F.; Adinolfi, E. Extracellular purines, purinergic receptors and tumor growth. Oncogene 2017, 36, 293-303. [CrossRef]

98. Vaupel, P.; Mayer, A. Hypoxia-Driven Adenosine Accumulation: A Crucial Microenvironmental Factor Promoting Tumor Progression. In Advances in Experimental Medicine and Biology; Elwell, C.E., Leung, T.S., Harrison, D.K., Eds.; Springer Science and Business Media LLC: Berlin, Germany, 2016; Volume 876, pp. 177-183.

99. Ohta, A.; Gorelik, E.; Prasad, S.J.; Ronchese, F.; Lukashev, D.; Wong, M.K.K.; Huang, X.; Caldwell, S.; Liu, K.; Smith, P.; et al. A2A adenosine receptor protects tumors from antitumor T cells. Proc. Natl. Acad. Sci. USA 2006, 103, 13132-13137. [CrossRef]

100. Beavis, P.A.; Divisekera, U.; Paget, C.; Chow, M.T.; John, L.B.; Devaud, C.; Dwyer, K.; Stagg, J.; Smyth, M.J.; Darcy, P.K. Blockade of A2A receptors potently suppresses the metastasis of CD73+ tumors. Proc. Natl. Acad. Sci. USA 2013, 110, 14711-14716. [CrossRef] [PubMed]

101. Stagg, J.; Divisekera, U.; Duret, H.; Sparwasser, T.; Teng, M.; Darcy, P.; Smyth, M. CD73-Deficient Mice Have Increased Antitumor Immunity and Are Resistant to Experimental Metastasis. Cancer Res. 2011, 71, 2892-2900. [CrossRef] [PubMed]

102. Vijayan, D.; Barkauskas, D.S.; Stannard, K.; Sult, E.; Buonpane, R.; Takeda, K.; Teng, M.W.L.; Sachsenmeier, K.; Hay, C.; Smyth, M.J. Selective activation of anti-CD73 mechanisms in control of primary tumors and metastases. Oncoimmunology 2017, 6, e1312044. [CrossRef]

103. Stagg, J.; Beavis, P.; Divisekera, U.; Liu, M.C.; Möller, A.; Darcy, P.; Smyth, M.; Diaconu, I.; Cerullo, V.; Hirvinen, M.L.; et al. CD73-Deficient Mice Are Resistant to Carcinogenesis. Cancer Res. 2012, 72, 2190-2196. [CrossRef] [PubMed]

104. Sorrentino, C.; Miele, L.; Porta, A.; Pinto, A.; Morello, S. Myeloid-derived suppressor cells contribute to A2B adenosine receptorinduced VEGF production and angiogenesis in a mouse melanoma model. Oncotarget 2015, 6, 27478-27489. [CrossRef] [PubMed]

105. Csoka, B.; Selmeczy, Z.; Koscso, B.; Nemeth, Z.H.; Pacher, P.; Murray, P.J.; Kepka-Lenhart, D.; Morris, S.M.; Gause, W.C.; Leibovich, S.J.; et al. Adenosine promotes alternative macrophage activation via A2A and A2B receptors. FASEB J. 2012, 26, 376-386. [CrossRef]

106. Perrot, I.; Michaud, H.-A.; Giraudon-Paoli, M.; Augier, S.; Docquier, A.; Gros, L.; Courtois, R.; Déjou, C.; Jecko, D.; Becquart, O.; et al. Blocking antibodies targeting the CD39/CD73 immunosuppressive pathway unleash immune responses in combination cancer therapies. Cell Rep. 2019, 27, 2411-2425. [CrossRef] [PubMed]

107. Chiu, D.K.-C.; Xu, I.M.-J.; Lai, R.K.-H.; Tse, A.P.-W.; Wei, L.L.; Koh, H.-Y.; Li, L.L.; Lee, D.; Lo, R.C.-L.; Wong, C.-M.; et al. Hypoxia induces myeloid-derived suppressor cell recruitment to hepatocellular carcinoma through chemokine (C-C motif) ligand 26. Hepatology 2016, 64, 797-813. [CrossRef]

108. Zhang, H.; Qian, D.Z.; Tan, Y.S.; Lee, K.; Gao, P.; Ren, Y.R.; Rey, S.; Hammers, H.; Chang, D.; Pili, R.; et al. Digoxin and other cardiac glycosides inhibit HIF-1 synthesis and block tumor growth. Proc. Natl. Acad. Sci. USA 2008, 105, 19579-19586. [CrossRef]

109. Wong, C.C.L.; Zhang, H.; Gilkes, D.M.; Chen, J.; Wei, H.; Chaturvedi, P.; Hubbi, M.E.; Semenza, G.L. Inhibitors of hypoxiainducible factor 1 block breast cancer metastatic niche formation and lung metastasis. J. Mol. Med. 2012, 90, 803-815. [CrossRef] [PubMed]

110. Scheuermann, T.H.; Tomchick, D.; Machius, M.; Guo, Y.; Bruick, R.K.; Gardner, K.H. Artificial ligand binding within the HIF2 PAS-B domain of the HIF2 transcription factor. Proc. Natl. Acad. Sci. USA 2009, 106, 450-455. [CrossRef]

111. Xu, J.; Zheng, L.; Chen, J.; Sun, Y.; Lin, H.; Jin, R.-A.; Tang, M.; Liang, X.; Cai, X. Increasing AR by HIF-2 $\alpha$ inhibitor (PT-2385) overcomes the side-effects of sorafenib by suppressing hepatocellular carcinoma invasion via alteration of pSTAT3, pAKT and pERK signals. Cell Death Dis. 2017, 8, e3095. [CrossRef]

112. Cho, H.; Du, X.; Rizzi, J.P.; Liberzon, E.; Chakraborty, A.A.; Gao, W.; Carvo, I.; Signoretti, S.; Bruick, R.K.; Josey, J.A.; et al. On-target efficacy of a HIF-2alpha antagonist in preclinical kidney cancer models. Nature 2016, 539, 107-111. [CrossRef]

113. Yang, S.-L.; Liu, L.-P.; Niu, L.; Sun, Y.-F.; Yang, X.-R.; Fan, J.; Ren, J.-W.; Chen, G.G.; Lai, P.B. Downregulation and pro-apoptotic effect of hypoxia-inducible factor 2 alpha in hepatocellular carcinoma. Oncotarget 2016, 7, 34571-34581. [CrossRef]

114. Sun, H.-X.; Xu, Y.; Yang, X.-R.; Wang, W.-M.; Bai, H.; Shi, R.-Y.; Nayar, S.K.; Devbhandari, R.P.; He, Y.-Z.; Zhu, Q.; et al. Hypoxia inducible factor 2 alpha inhibits hepatocellular carcinoma growth through the transcription factor dimerization partner 3/ E2F transcription factor 1-dependent apoptotic pathway. Hepatology 2012, 57, 1088-1097. [CrossRef] [PubMed] 
115. Méndez-Blanco, C.; Fernández-Palanca, P.; Fondevila, F.; González-Gallego, J.; Mauriz, J.L. Prognostic and clinicopathological significance of hypoxia-inducible factors $1 \alpha$ and $2 \alpha$ in hepatocellular carcinoma: A systematic review with meta-analysis. Ther. Adv. Med. Oncol. 2021, 13, 1758835920987071. [CrossRef] [PubMed]

116. Wang, X.; Dong, J.; Jia, L.; Zhao, T.; Lang, M.; Li, Z.; Lan, C.; Li, X.; Hao, J.; Wang, H.; et al. HIF-2-dependent expression of stem cell factor promotes metastasis in hepatocellular carcinoma. Cancer Lett. 2017, 393, 113-124. [CrossRef] [PubMed]

117. Bangoura, G.; Liu, Z.S.; Qian, Q.; Jiang, C.Q.; Yang, G.F.; Jing, S. Prognostic significance of HIF-2alpha/EPAS1 expression in hepatocellular carcinoma. World J. Gastroenterol. 2007, 13, 3176-3182. [CrossRef]

118. Bao, M.H.-R.; Yang, C.; Tse, A.P.-W.; Wei, L.; Lee, D.; Zhang, M.S.; Goh, C.C.; Chiu, D.K.-C.; Yuen, V.W.-H.; Law, C.-T.; et al. Genome-wide CRISPR-Cas9 knockout library screening identified PTPMT1 in cardiolipin synthesis is crucial to survival in hypoxia in liver cancer. Cell Rep. 2021, 34, 108676. [CrossRef] 